\title{
Complex conductivity of soils
}

Revil, A.; Coperey, A.; Shao, Z.; Florsch, N.; Fabricius, Ida Lykke; Deng, Y.; Delsman, J.; Pauw, P.; Karaoulis, M.; de Louw, P.G.B.

Total number of authors:

14

Published in:

Water Resources Research

Link to article, DOI:

10.1002/2017WR020655

Publication date:

2017

Document Version

Peer reviewed version

Link back to DTU Orbit

Citation (APA):

Revil, A., Coperey, A., Shao, Z., Florsch, N., Fabricius, I. L., Deng, Y., Delsman, J., Pauw, P., Karaoulis, M., de Louw, P. G. B., van Baaren, E. S., Dabekaussen, W., Menkovic, A., \& Gunnink, J. L. (2017). Complex conductivity of soils. Water Resources Research, 53(8), 7121-7147. [WRCR22832].

https://doi.org/10.1002/2017WR020655

\section{General rights}

Copyright and moral rights for the publications made accessible in the public portal are retained by the authors and/or other copyright owners and it is a condition of accessing publications that users recognise and abide by the legal requirements associated with these rights.

- Users may download and print one copy of any publication from the public portal for the purpose of private study or research.

- You may not further distribute the material or use it for any profit-making activity or commercial gain

- You may freely distribute the URL identifying the publication in the public portal 


\section{Complex conductivity of soils}

Revil A. (1), A. Coperey (1) ${ }^{\mathbb{D}}$, Z. Shao (1, 2), N. Florsch (3), I.L. Fabricius (4), Y. Deng (1, 5),

J. Delsman (5) ${ }^{\mathbb{1}}$, P. Pauw (5), M. Karaoulis (5),P. G. B. de Louw (5), E.S. van Baaren (5), W.

Dabekaussen (6), A. Menkovic (6), and J. L. Gunnink (6)

(1) Université Savoie Mont Blanc, CNRS, IRD, IFSTTAR, ISTerre, F-73000 Chambéry, France.

(2) School of Safety Engineering, China University of Mining and Technology, Xuzhou, Jiangsu, China

(3) Université Paris 06,Sorbonne Universités, IRD, UMI 209, UMMISCO and UMR 7619 METIS, Paris, France

(4) DTU, Technical University of Denmark, Department of Civil Engineering, Lyngby, Denmark

(5) Key Laboratory of Surficial Geochemistry of Ministry of Education, School of Earth Sciences and Engineering, Nanjing University, Nanjing 210023, China

(6) DELTARES, Utrecht, The Netherlands

(7) TNO-Geological Survey of the Netherlands, Princetonlaan 6, 3508 TA Utrecht, the Netherlands

Keywords: Spectral induced polarization, quadrature conductivity, surface conductivity, cation exchange capacity

Corresponding author: André Revil (andre.revil@univ-smb.fr)

Short title: Complex conductivity of soils

Emails: Pieter.Pauw@deltares.nl; joost.delsman@deltares.nl; andre.revil@,univ-smb.fr;

antoine.coperey@gmail.com; sz10808@126.com; nicolas.florsch@gmail.com;

Marios.Karaoulis@deltares.nl; Perry.deLouw@deltares.nl; Esther.vanBaaren@deltares.nl; jan.gunnink@tno.nl; willem.dabekaussen@tno.nl; armin.menkovic@tno.nl; ilfa@,byg.dtu.dk; dg1529039@smail.nju.edu.cn

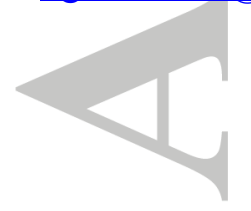

Intended for publication in Water Resources Research

This article has been accepted for publication and undergone full peer review but has not been through the copyediting, typesetting, pagination and proofreading process which may lead to differences between this version and the Version of Record. Please cite this article as an 'Accepted Article', doi: 10.1002/2017WR 020655 
Abstract. The complex conductivity of soil remains poorly known despite the growing importance of this method in hyrogeophysics. In order to fill this gap of knowledge, we investigate the complex conductivity of 71 soils samples (including 4 peat samples) and one clean sand in the frequency range $0.1 \mathrm{Hertz}$ to $45 \mathrm{kHz}$. The soil samples are saturated with 6 different $\mathrm{NaCl}$ brines with conductivities $\left(0.031,0.53,1.15,5.7,14.7\right.$, and $22 \mathrm{~S} \mathrm{~m}^{-1}, \mathrm{NaCl}$, $25^{\circ} \mathrm{C}$ ) in order to determine their intrinsic formation factor and surface conductivity. This dataset is used to test the predictions of the dynamic Stern polarization model of porous media in terms of relationship between the quadrature conductivity and the surface conductivity. We also investigate the relationship between the normalized chargeability (the difference of inphase conductivity between two frequencies) and the quadrature conductivity at the geometric mean frequency. This dataset confirms the relationships between the surface conductivity, the quadrature conductivity, and the normalized chargeability. The normalized chargeability depends linearly on the cation exchange capacity and specific surface area while the chargeability shows no dependence on these parameters. These new data and the dynamic Stern layer polarization model are observed to be mutually consistent. Traditionally, in hydrogeophysics, surface conductivity is neglected in the analysis of resistivity data. The relationships we have developed can be used in field conditions to avoid neglecting surface conductivity in the interpretation of DC resistivity tomograms. We also investigate the effects of temperature and saturation and, here again, the dynamic Stern layer predictions and the experimental observations are mutually consistent.

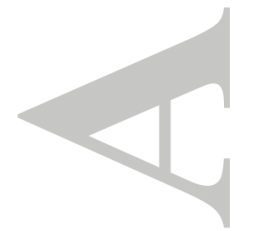




\section{Introduction}

Induced polarization (or complex conductivity) tomography is a geophysical imaging technique based on the study of the low-frequency $(<10 \mathrm{kHz})$ polarization processes occurring in porous media. It extends the classical Direct Current (DC) resistivity method, which has been broadly used in hydrogeophysics in the last two decades (e.g., Johnson et al. [2010]; Binley et al. [2015]). In spectral induced polarization, the frequency dependence of both electrical resistivity and the phase shift between the electrical field and the current are independently measured and analyzed over a range of frequencies (e.g., Kemna et al. [2012]). The amplitude of resistivity (impedance) and the phase can be recasted into a complex conductivity. Under an applied (primary) electrical field, its in-phase (real) component characterizes the electromigration of the charge carriers while its quadrature (out-of-phase, imaginary) component is used to describe local accumulations of electrical charge carriers resulting in the polarization of the porous materials [Vinegar and Waxman, 1984]. In siliciclastic materials, their ability to store reversibly electrical charges is related to the polarization of the electrical double layer surrounding the mineral grains and possibly some membrane polarization phenomena [Vinegar and Waxman, 1984].

Induced polarization has many applications in hydrogeophysics including inference of hydraulic properties (Binley et al. [2005]; Weller et al. [2010], Joseph et al. [2015]; Nordsiek et al. [2015]), facies discrimination [Revil et al., 2013], the detection of contaminants in soils (e.g., Sogade et al. [2006], Flores Orozco et al. [2012], Schwartz and Furman [2012], Schmutz et al. [2012], Chen et al. [2013]), and the detection of cracks (e.g., Okay et al. [2013]). Induced polarization has shown also a unique capability to monitor non-intrusively sorption processes in the electrical double layer (Vaudelet et al. [2011a, b], Hao et al. [2016]) and precipitation of metallic particles during redox-controlled reactions (e.g., Mewafy et al. 
[2013], Abdulsamad [2017]). Induced polarization has also become a tool that can be used to study the cryosphere in shallow formations [Grimm and Stillman, 2015].

In the growing literature dedicated to hydrogeophysics and for the study of the critical zone, the formation factor is often erroneously defined as the pore water conductivity divided by the conductivity of the porous material. With such a definition, the (apparent) formation factor is not a textural parameter of porous media but would depend on the salinity or total dissolved content (TDS) of the pore water. Surface conductivity in the electrical double layer surrounding the mineral grains needs to be accounted for (e.g., Waxman and Smits [1968], Vinegar and Waxman [1984], Okay et al. [2014]). Surface conductivity is often neglected in hydrogeophysics as being an important contributor to the overall electrical conductivity of siliciclastic materials while its role has been recognized for many decades in soil sciences (e.g., Shainberg et al. [1980], Friedman [2005] and references therein) and in well logging analysis (e.g., Waxman and Smits [1968]). This practice of neglecting surface conductivity is however erroneous especially in freshwater environments for which the surface conductivity can easily dominate the conductivity of the porous materials. For instance Revil et al. [2014b] showed that the (apparent) formation factor can strongly underestimate the true (intrinsic) formation factor even for a perfectly clean (i.e., clay-free) sandstone like the Fontainebleau sandstone. This implies in turn that a growing number of publications in hydrogeophysics are not correct in their interpretation of resistivity tomograms. For various applications in hydrogeophysics, we need to obtain an intrinsic formation factor corrected for surface conductivity. In laboratory conditions, the (intrinsic) formation factor is traditionally obtained by measuring the electrical conductivity of a core samples at different brine conductivities [e.g., Waxman and Smits, 1968; Vinegar and Waxman, 1984]. Revil [2013b] and Weller et al. [2013] developed new relationships between the quadrature and surface conductivities and 
following Weller et al. [2013], this relationship can be used to determine the intrinsic formation factor at a single brine conductivity.

While much work has been done in describing the electrical conductivity of soils (see a review in Friedman [2005]), few publications have targeted the complex conductivity of these porous materials (see Schwartz and Furman [2012], Nordsiek et al. [2015] for limited investigations with few core samples). In the present paper, we test the dynamic Stern layer model developed by Revil and collaborators to describe the complex conductivity of brinesaturated clayey soils. Then, we develop the first extensive database of complex conductivity of soil samples with 71 samples analyzed plus one clean silica sand. Our goal is to test the relationships between the surface and quadrature conductivities as well with the normalized chargeability. We will also discuss the dependence of the normalized chargeability with the cation exchange capacity and specific surface area, two very important properties of soils in agriculture (e.g., Saidi [2012]).

\section{Dynamic Stern layer polarization model}

\subsection{Properties of the complex conductivity}

In order to build an appropriate complex conductivity function, few elements need to be taken into account. Minerals in soils have an intrinsic charge on their surface and are coated by an electrical double layer comprising the Stern and diffuse layers (Figure 1). This double layer is responsible for both an excess conduction called surface conductivity (Figure 1) and the polarization of the pore space and the grains (Figure 2).

The frequency dependence of the real and imaginary parts of the complex conductivity corresponding to induced polarization phenomena, i.e., $\sigma^{\prime}$ and $\sigma^{\prime \prime}$, should obey the KramersKronig relationships [Kronig, 1926; Kramers, 1927; Kronig, 1942], which are based on the causality principle. An interesting account of the early history of these relationships can be 
found in Bohren [2010]. In addition, the value of the in-phase conductivity should be bounded by the value of the DC conductivity $\sigma_{0}$ (at zero frequency) and the value of a high frequency conductivity $\sigma_{\infty}$. By high frequency, we mean a frequency close to the $\mathrm{MHz}$ (see discussion in Vinegar and Waxman [1984]).

The quadrature conductivity $\sigma^{\prime \prime}$ should go to zero both in DC conditions (zero frequency) and at very high frequencies (i.e., above the $\mathrm{MHz}$ ). Experiments show however that at high frequencies, the magnitude of the quadrature conductivity keeps increasing because of the superposition with another polarization mechanism, namely the Maxwell Wagner polarization [Revil, 2013a] plus dielectric polarization phenomena. In this case, the effective quadrature conductivity should be written as $\sigma^{\prime \prime}{ }_{\text {eff }}(\omega)=\sigma "-\omega \varepsilon_{\infty}$ where $\varepsilon_{\infty}$ denotes actually the low-frequency permittivity of the Maxwell Wagner polarization or the dielectric permittivity in absence of Maxwell Wagner polarization.

Note that because the low and high frequency limits of $\sigma$ "are equal to zero (e..g., Vinegar and Waxman [1984]), the bounds $\sigma_{0}$ and $\sigma_{\infty}$ are also the bounds for the magnitude of the complex conductivity defined by $\sigma=\left(\sigma^{\prime 2}+\sigma^{\prime 2}\right)^{1 / 2}$. The conductivity $\sigma_{\infty}$ is the instantaneous conductivity of a material, i.e., the conductivity experienced in Ohm's law right after the application of an electrical field. At the opposite, the conductivity $\sigma_{0}$ is the DC conductivity obtained once all the polarization phenomena have fully established at all the polarizable length scales of the porous material. In these conditions, some of charge carriers (of the inner part of the electrical double layer) are blocked at the end of these polarization length scales (an example is shown in Figure 2 for a spherical grain). Another way to see this behavior is that at low frequencies, the polarization creates an electrical field (or a current density) that opposes the applied (primary) electrical field (or primary current density). This polarization phenomenon is however not dielectric per se. The reduction of the total electrical 
field at low frequencies is responsible for the fact that $\sigma_{0} \leq \sigma_{\infty}\left(\sigma_{0}=\sigma_{\infty}\right.$ in absence of polarization mechanism). We can also write $\sigma_{0}=\sigma_{\infty}(1-M)$, i.e., the DC conductivity is the instantaneous conductivity minus the effect of polarization described by the chargeability $M$ (dimensionless).

At this point, we have said nothing about the physical mechanism of low frequency polarization. In Figure 2, we focus on the polarization of the Stern layer. Figure 2 illustrates that all the charge carriers are mobile just after the application of an electrical field (at $t=0^{+}$) and that some of the charge carriers are blocked at the edge of the grains for a very long time ( $t \rightarrow+\infty$ ). Note that physically, the real part (in phase component) of the conductivity $\sigma^{\prime}$ refers to electromigration processes, i.e., the transport of the charge carriers driven by the electrical field, both in the pore water and along the electrical double layer coating the surface of the grains. The imaginary (quadrature) component $\sigma$ " refers to (reversible) charge accumulation like in a capacitor and is associated with the polarization of the Stern layer.

In Figure 2, the relaxation time of the problem $\tau$ corresponds to the relaxation time of the problem. Once the primary electrical field or current is removed, the process of polarization corresponds to the diffusion of the accumulated charge carriers to their equilibrium situation corresponding to Figure 2a. This process is a classical electrochemical membrane polarization/potential mechanism similar to the well-established self-potential problem or concentration polarization (see Mao and Revil [2016] for a discussion on this topic).

From Figure 2, it is obvious that the distribution of the polarization length scales would correspond to the grain size distribution, perhaps in some cases to a pore size distribution, both being interrelated in granular porous media. We denote this distribution $h(\tau)$. The complex conductivity would result from the superposition of spectra associated with the polarization of the individual length scales. In doing such a convolution, the right 
kernel needs to be known. Usually in geophysics, many researchers use a Debye function as kernel. For the reasons discussed in details in Revil et al. [2014a], we believe that the correct kernel for porous media is close to a Warburg function (i.e., a Cole Cole conductivity function, Cole and Cole [1941], with a Cole Cole exponent of $1 / 2$ while the Debye function would corresponds to a Cole Cole function with an exponent of 1). Physically, this means that the polarization of the Stern layer is not equivalent to a perfect capacitance (which would correspond to a Debye transfer function for the impedance) but to a "leaking" capacitance due to sorption/desorption of the counterions during the polarization process.

\subsection{Complex conductivity model}

In the following, a harmonic external electrical field of the form $\mathbf{E}=\mathbf{E}_{0} \exp (+i \omega t)$ is applied to the porous material. In the realm of the dynamic Stern layer model, the complex conductivity of a porous granular material without metallic grains is given by [Revil, 2013a, b; Revil et al., 2014a]

$$
\sigma^{*}(\omega)=\sigma_{\infty}\left(1-M \int_{0}^{\infty} \frac{h(\tau)}{1+(i \omega \tau)^{1 / 2}} d \tau\right)+i \omega \varepsilon_{\infty},
$$

where $\omega$ denotes the angular frequency $\left(\operatorname{rad~s}^{-1}\right), \varepsilon_{\infty}$ denotes the high frequency permittivity (in $\mathrm{F} \mathrm{m}^{-1}=\mathrm{A} \mathrm{s} \mathrm{V}^{-1} \mathrm{~m}^{-1}$ actually the low frequency part of the Maxwell Wagner polarization and the dielectric constant of the material), $\tau$ is a time constant (also called a relaxation time since corresponding to a diffusion process as discussed above), $M=\left(\sigma_{\infty}-\sigma_{0}\right) / \sigma_{\infty}$ is the dimensionless chargeability, $\sigma_{0}$ and $\sigma_{\infty}$ denoting the DC $(\omega=0)$ and high-frequency electrical conductivities (in $\mathrm{S} \mathrm{m} \mathrm{m}^{-1}=\mathrm{A} \mathrm{V}^{-1} \mathrm{~m}^{-1}$ ), respectively, and $h(\tau)$ denotes a (normalized) probability density for distribution of the time constants of the material. Equation (1) satisfies all the criteria described in Section 2.1. This equation can be sketched with the equivalent 
circuit shown in Figure 3 or the simplified circuit shown in Figure 4 (see also the constant phase model described in Appendix A).

We define a normalized chargeability as $M_{n}=M \sigma_{\infty}=\sigma_{\infty}-\sigma_{0}$, i.e., defined as the difference between the high-frequency conductivity and the low-frequency (DC) conductivity. The introduction of such a normalized chargeability, with units in $\mathrm{S} \mathrm{m}^{-1}$, may seem inappropriate to some geophysicists that are experienced with the use of the chargeability (which is dimensionless). In hydrogeophysics, chargeability is commonly normalized by resistivity to remove in order to remove the fingerprint of resistivity on the inverted chargeability tomograms (see discussions in Slater and Glaser [2003] and Mansoor and Slater [2007]). In addition, according to the dynamic Stern layer model, $M_{n}$ is proportional to the cation exchange capacity of the material as discussed by Mao et al. [2016], and therefore to the clay content. This is not the case with the chargeability itself as discussed at the end of this paper. However, in the presence of metallic particles (e.g., pyrite, magnetite, slag), the unitless chargeability remains the key parameters to plot since it is directly related to the volume content of metallic particles.

The high and low frequency conductivities can be obtained through a volume averaging method as underlined by Revil [2013a]. In the present paper, the relationships for the low and high frequency electrical conductivity are given by what we call below the linear conductivity model. For materials characterized by high porosities, the expressions obtained by Revil [2013a] are

$$
\begin{aligned}
& \sigma_{0}=\frac{1}{F} \sigma_{w}+\left(\frac{1}{F \phi}\right) \rho_{g} \beta_{(+)}(1-f) \mathrm{CEC}, \\
& \sigma_{\infty}=\frac{1}{F} \sigma_{w}+\left(\frac{1}{F \phi}\right) \rho_{g}\left[\beta_{(+)}(1-f)+\beta_{(+)}^{S} f\right] \mathrm{CEC},
\end{aligned}
$$

where $\sigma_{w}$ (in $\mathrm{S} \mathrm{m}^{-1}$ ) denotes the pore water conductivity, $F$ (dimensionless) the intrinsic formation factor, $f$ (dimensionless) denotes the partition coefficient (fraction of counterions in 
the Stern layer versus the entire double layer), $\rho_{g}$ is the grain density (in $\mathrm{kg} \mathrm{m}^{-3}$, typically $\rho_{g}=$ $2650 \mathrm{~kg} \mathrm{~m}^{-3}$ for sedimentary rocks), and CEC is the cation exchange capacity (in $\mathrm{C} \mathrm{kg}^{-1}$ ). The values of the mobility of ions in diffuse layer of sedimentary rocks is the same as in the bulk pore water with $\beta_{(+)}\left(\mathrm{Na}^{+}, 25^{\circ} \mathrm{C}\right)=5.2 \times 10^{-8} \mathrm{~m}^{2} \mathrm{~s}^{-1} \mathrm{~V}^{-1}$. Finally $\beta_{(+)}^{S}$ describes the mobility of the counterions in the Stern layer which is expected to be equal or small than the mobility of the same cations in the diffuse layer. Equations (2) and (3) connect the conductivity (e.g., measured in the field using galvanometric or induction-based electromagnetic techniques), the conductivity of the pore water $\sigma_{w}$, the (intrinsic) formation factor $F$, the porosity $\phi$, and the surface conductivity due to electrical conductivity associated mostly with clay minerals (see Figures 1 to 3). From equation (2) and (3), it is easy to show that the chargeability is expected to be a strong function of the pore water conductivity. The effect of pore connectivity and grain shape are encapsulated into the definition of the formation factor (Sen et al. [1981] and Bernabé et al. [2011]). They are likely to influence the relaxation times as well. Note that equations (2) and (3) are strictly valid only at high salinity for which the local electrical field is dominated by the distribution of the bulk conductances (e.g., Johnson et al. [1986], Bernabé and Revil [1995]). The high salinity domain, in this context, is not a domain for which surface conductivity is negligible but a domain for which the surface conductivity is lower than the bulk conductivity.

For completeness, and in the context of the dynamic Stern layer model, each time constant $\tau$ of the distribution $h(\tau)$ is associated with a pore size or grain size $r$ (see discussions in Revil and Florsch [2010] and Revil et al. [2012]) according to

$$
\tau=\frac{r^{2}}{2 D_{(+)}^{S}}
$$

where $D_{(+)}^{S}$ denotes the diffusion coefficient of the counterions in the Stern layer (expressed in $\left.\mathrm{m}^{2} \mathrm{~s}^{-1}\right)$. Note that for soils, as opposed to consolidated rocks, referring to the grains is probably 
more realistic than referring to pores. The value of this diffusion coefficient $D_{(+)}^{S}$ should relate to the mobility of the counterions in the Stern layer, $\beta_{(+)}^{S}$, by the Nernst-Einstein relationship $D_{(+)}^{S}=k_{b} T \beta_{(+)}^{S} /\left|q_{(+)}\right|$, where $T$ denotes the absolute temperature (in K), $k_{b}$ denotes the Boltzmann constant $\left(1.3806 \times 10^{-23} \mathrm{~m}^{2} \mathrm{~kg} \mathrm{~s}^{-2} \mathrm{~K}^{-1}\right),\left|q_{(+)}\right|$is the charge of the counterions in the Stern layer coating the surface of the grains $\left(\left|q_{(+)}\right|=e\right.$ where $e$ is the elementary charge for $\left.\mathrm{Na}^{+}\right)$. Therefore, according to equations (4), the probability density $h(\tau)$ can be transformed into a grain size (or pore size) probability density or (normalized) distribution, which would control in turn the transition between low and high frequencies in equation (1). Note that if the soil has a fractal nature for instance in terms of grain size distribution (e.g., Hyslip and Vallejo [1997]; Ahmadi et al. [2011]), we can expect the complex conductivity to be characterized a very broad distribution of relaxation times so that the phase may appear rather flat at least over few decades in frequency [Vinegar and Waxman, 1984]. We will come back to this point below (in terms of what we call Drake's model) since it calls for simplification of the model.

As checked later in this paper, the in-phase conductivity of soils depends slightly on the frequency. In the context of the dynamic Stern layer model, this dependence is purely related to the contribution of the Stern layer and we can write,

$$
\sigma^{\prime}(\omega)=\frac{1}{F} \sigma_{w}+\sigma_{S}(\omega)
$$

where $\sigma_{S}(\omega)$ (in $\mathrm{S} \mathrm{m}^{-1}$ ) denotes a frequency dependent surface conductivity. This surface conductivity takes place in the electrical double layer coating the surface of the grains and comprises two contributions: one from the diffuse layer (frequency independent) and one from the Stern layer (which is frequency dependent) (Figure 1). This surface conductivity has low-frequency and high frequency asymptotic values given by 


$$
\begin{aligned}
& \sigma_{S}^{0}=\left(\frac{1}{F \phi}\right) \rho_{g} \beta_{(+)}(1-f) \mathrm{CEC}, \\
& \sigma_{S}^{\infty}=\left(\frac{1}{F \phi}\right) \rho_{g}\left[\beta_{(+)}(1-f)+\beta_{(+)}^{S} f\right] \mathrm{CEC},
\end{aligned}
$$

respectively.

In equation (6), the DC surface conductivity is purely controlled by the diffuse layer. The contribution of the Stern layer is zero because the counterions remains stuck at the boundaries of the grains. At the opposite, at high frequencies both the the Stern and diffuse layers contribute to surface conductivity. In the context of the linear conductivity model described by equations (2) and (3), we have

$$
\begin{gathered}
M_{n} \equiv \sigma_{\infty}-\sigma_{0}, \\
M_{n}=\sigma_{s}^{\infty}-\sigma_{S}^{0}, \\
M_{n}=\left(\frac{1}{F \phi}\right) \rho_{g} \beta_{(+)}^{S} f \mathrm{CEC} .
\end{gathered}
$$

Therefore the normalized chargeability is exactly the difference between the high frequency surface conductivity and the low frequency surface conductivity (note that this will not be true for a non-linear conductivity model). Equation (10) shows that the normalized chargeability depends on the properties of the grains ( $\rho_{g}$ and CEC), the properties of the Stern layer $\left(\beta_{(+)}^{S}\right.$ and $f$ ), and the texture of the porous material through the dependence of both the surface conductivity and the normalized chargeability on the formation factor $F$. Note that the salinity dependence of the normalized chargeability comes from the salinity dependence of the partition coefficient $f$ and the salinity dependence of the tortuosity of the conduction paths at very low salinities for which the linear conductivity model is not valid [Niu et al., 2016]. We also note that the phase lag $\varphi=\tan \left(\sigma^{\prime \prime} / \sigma^{\prime}\right) \approx \sigma^{\prime \prime} / \sigma^{\prime}$ and the chargeability $M=M_{n} / \sigma_{\infty}$ cannot be considered as true polarization parameters. They both represent the ratio between a true polarization parameter (respectively, $\sigma^{\prime \prime}$ and $M_{n}$ ) and the conductivity (respectively, $\sigma^{\prime}$ 
and $\left.\sigma_{\infty}\right)$. As detailed by Revil et al. [2015a, b], this concept is true only as long as the material does not contain metallic particles.

We conclude this section with the following remarks. The surface conductivity and the normalized chargeability can be difficult to assess. The surface conductivity is indeed difficult

to determine because the linear conductivity model (with bulk and surface conductivity working in parallel) is only valid when the surface conductivity is small (but non-negligible). When surface conductivity is high, this high salinity assumption is not valid anymore and the relationship between the conductivity of the porous material and the pore water conductivity is becoming non-linear (example of this non-linear behavior will be discussed for soils below). The normalized chargeability may be also difficult to accurately measure since it requires very broadband measurements. In time domain induced polarization, the normalized chargeability can be measured but requires that all the polarization length scales have been fully polarized, which can be only achieved through a long duration (100 to $200 \mathrm{~s}$ ) of the primary current injection. The quadrature conductivity is easily measurable but its value is frequency dependent. In addition at high frequencies, $>1 \mathrm{kHz}$, the quadrature conductivity associated with the polarization of the double layer of the grains can be masked by the Maxwell Wagner and dielectric polarization.

\subsection{Normalized chargeability versus quadrature conductivity}

The frequency effect $F E$ is defined from the variation with the frequency of in-phase conductivity according to (Appendix A):

$$
\mathrm{FE}=\frac{\sigma^{\prime}(D \omega)-\sigma^{\prime}(\omega)}{\sigma^{\prime}(D \omega)}
$$

and therefore characterizes the change in in-phase conductivity between two angular frequencies $\omega$ and $D \omega$, and $\log (D)$ denotes the number of decades separating high and low frequencies. This frequency effect can be related to the phase angle $\varphi$ measured at the 
geometric frequency $D^{1 / 2} \omega$ [Shuey and Johnson 1973, and Van Voorhis et al. 1973] (see details in Appendix A)

$$
\mathrm{FE} \approx-\frac{2}{\pi} \varphi \ln D, \text { for }|\varphi|<<1 .
$$

Equations (11) and (12) can be used to determine the relationship between the quadrature conductivity and the normalized chargeability. We assume that the conductivity itself is not a strong function of the frequency, which is the case for porous rocks (see Vinegar and Waxman [1984]) and soils. Then, we consider that the quadrature conductivity is determined close to the peak frequency used as the geometric mean frequency between a low frequency for which the conductivity is close to $\sigma_{0}$ and a high frequency for which the conductivity is close to $\sigma_{\infty}$. In this case, equation (12) can be written as an equation for the normalized chargeability and the quadrature conductivity,

$$
M_{n} \approx-\left(\frac{2}{\pi} \ln D\right) \sigma^{\prime \prime}
$$

Following our previous paper [Revil et al. 2015c], we can define a linear relationship between the quadrature conductivity and the normalized chargeability,

$$
\sigma^{\prime \prime} \approx-\frac{M_{n}}{\alpha}
$$

where $\alpha$ is a constant. Comparing Equations (13) and (14), we have,

$$
\alpha \approx-\left(\frac{2}{\pi} \ln D\right) .
$$

If we assume that high and low frequencies are separated by 6 decades $\left(D=10^{6}\right)$, we obtain $\alpha \approx 8.8$ while if we use 7 decades, we obtain $\alpha \approx 10.3$. We will consider therefore that $\alpha$ is typically in the range 5-10.

\subsection{Quadrature conductivity versus surface conductivity}

Following Revil et al. (2015c), we use the following definition for the dimensionless number R: 


$$
\mathrm{R} \equiv \frac{M_{n}}{\sigma_{S}^{\infty}} \approx-\alpha\left(\frac{\sigma^{\prime \prime}}{\sigma_{S}^{\infty}}\right),
$$

and therefore $-\sigma^{\prime \prime} / \sigma_{S}^{\infty}=\mathrm{R} / \alpha$. Using equations (7) and (10), this dimensionless number R can be related to the partition coefficient $f$ (e.g., Revil et al. [2015c]) by

$$
\mathrm{R}=\frac{\beta_{(+)}^{S} f}{\left[\beta_{(+)}(1-f)+\beta_{(+)}^{S} f\right]} .
$$

In the context of field resistivity interpretation, equation (16) is of paramount importance since it can be used to assess surface conductivity from the measurement of the quadrature conductivity and the knowledge of the value of the dimensionless number $\mathrm{R}$, which is roughly a constant as discussed below.

\subsection{A modified Drake's model}

Drake's model corresponds to the constant phase model explored in Appendix A and sketched in Figure 4. This is also the type of model used by Vinegar and Waxman [1984] to model the complex conductivity of shaly sands. The rational for this model is as follow. We assume that the distribution of polarization length scales is very broad e.g., fractal at least between two lengths scales. In this case, the phase is expected to be rather flat as discussed in details by Vinegar and Waxman [1984] in a frequency range. We will see later that if even for our soil samples, the phase is not completely flat with the frequency. Still, Drake's model offers a very good way to connect the frequency effect FE and the phase or alternatively the normalized chargeability and the quadrature conductivity. In the context of Drake's model, our approach leads to define a surface conductivity, a normalized chargeability, and a quadrature conductivity as

$$
\begin{aligned}
& \sigma_{S}^{\infty}=\left(\frac{1}{F \phi}\right) B \rho_{g} \mathrm{CEC}, \\
& M_{n}=\left(\frac{1}{F \phi}\right) \lambda \rho_{g} \mathrm{CEC},
\end{aligned}
$$




$$
\sigma^{\prime \prime}=-\left(\frac{1}{F \phi}\right) \frac{\lambda}{\alpha} \rho_{g} \mathrm{CEC}
$$

respectively, where $B \equiv \beta_{(+)}(1-f)+\beta_{(+)}^{S} f$ denotes the apparent mobility of the counterions for surface conduction (this parameter is close to the mobility $B$ introduced by Waxman and Smits [1968] for the in-phase conductivity) and $\lambda=\beta_{(+)}^{S} f$ denotes the apparent mobility of the counterions for the polarization associated with the quadrature conductivity ( $\lambda$ is close to the apparent mobility introduced by Vinegar and Waxman [1984] for the quadrature conductivity). Note that the dimensionless number $\mathrm{R}$ is also given by $\mathrm{R}=\lambda / B$. We also neglect below the salinity dependence of the surface and quadrature conductivities (Weller and Slater [2012], Weller et al. [2013], Niu et al. [2016]) but this dependence could be easily added to our model using the approach developed in Niu et al. [2016]. The equivalent linear circuit of a soil can be sketched as in Figure 4 and can be seen as two resistances in parallel to a capacitance.

For field applications, it is important to expand the previous equations to include explicitly the effect of temperature. For soils, we are interested in the temperature range 0$50^{\circ} \mathrm{C}$ for which we can consider linear temperature variations [Waxman and Smits, 1968; Vinegar and Waxman, 1984; Revil et al., 1998]. This yields

$$
\begin{gathered}
\sigma_{w}(T)=\sigma_{w}\left(T_{0}\right)\left[1+\alpha_{w}\left(T-T_{0}\right)+\ldots\right], \\
\lambda(T)=\lambda\left(T_{0}\right)\left[1+\alpha_{S}\left(T-T_{0}\right)+\ldots\right], \\
B(T)=B\left(T_{0}\right)\left[1+\alpha_{S}\left(T-T_{0}\right)+\ldots\right],
\end{gathered}
$$

which corresponds to the temperature variations of $\beta_{(+)}$(for equation 21) and $\beta_{(+)}^{S}$ (for equations 22 and 23), respectively, $T_{0}=25^{\circ} \mathrm{C}$, and $\alpha_{w}$ and $\alpha_{S}$ denote the sensitivity coefficients to temperature for the viscosity of the free water and bound water, respectively (typically for water $\alpha_{w} \approx 0.020{ }^{\circ} \mathrm{C}^{-1}$ ). Equations (21) to (23) implies that the surface 
conductivity, the normalized chargeability, and the quadrature conductivity depends on the temperature as

$$
\begin{aligned}
& \sigma_{S}^{\infty}(T)=\sigma_{S}^{\infty}\left(T_{0}\right)\left[1+\alpha_{S}\left(T-T_{0}\right)+\ldots\right], \\
& M_{n}(T)=M_{n}\left(T_{0}\right)\left[1+\alpha_{S}\left(T-T_{0}\right)+\ldots\right], \\
& \sigma^{\prime \prime}(T)=\sigma^{\prime \prime}\left(T_{0}\right)\left[1+\alpha_{S}\left(T-T_{0}\right)+\ldots\right] .
\end{aligned}
$$

The chargeability is expected to be temperature independent, i.e., $\partial M / \partial T=0$. Again this is true only for the constant phase model for which there is no expected effect of the influence of the temperature on the relaxation times in the spectra.

Finally, another parameter to take into account is the effect of water saturation $s_{w}$ (with $0 \leq s_{w} \leq 1$ ). Using the analysis made by Revil [2013], we arrive quickly at the following explicit dependencies with the water saturation:

$$
\begin{aligned}
& \sigma^{\prime}\left(s_{w}\right)=\frac{1}{F} s_{w}{ }^{n} \sigma_{w}+s_{w}{ }^{n-1} \sigma_{S}, \\
& M_{n}\left(s_{w}\right)=\left(\frac{1}{F \phi}\right) s_{w}{ }^{p} \lambda \rho_{g} \mathrm{CEC}, \\
& \sigma^{\prime \prime}\left(s_{w}\right)=-\left(\frac{1}{F \phi}\right) s_{w}{ }^{p} \frac{\lambda}{\alpha} \rho_{g} \mathrm{CEC},
\end{aligned}
$$

with $p=n-1$ (see Vinegar and Waxman [1984] and Revil [2013] for some discussion on this subject). One of the predictions of equations (27) and (29) is that low salinity, the phase is expected to be independent of the saturation or equivalently the in-phase and quadrature conductivities are expected to have the same dependence with saturation. As explained for temperature, these dependencies are only correct for very flat spectra and he linear conductivity model.

\section{Material and methods}




\subsection{Samples}

In May 2016, we collected 71 sediment samples at 8 different locations on the

Walcheren peninsula; a deltaic area in the southwestern part of the Netherlands (Figure 5a).

We used a hand auger to drill above the water table and a piston sampler and gouge auger for samples below the water table (Figure 5b). The depth of the water table ranged from 1-4 m below ground level. The drilling depth ranged from 3 to $8.5 \mathrm{~m}$ below ground level and the drilling diameter was about $7 \mathrm{~cm}$. At each location we made a lithological description of the sediment in the field using the GEOTOP classification system [Stafleu et al., 2011]. Many drillings showed lithological heterogeneity (layering) on a very small scale (cm to $\mathrm{dm}$ ). We selected homogenous sections to sample about $300 \mathrm{~cm}^{3}$ of sediment. We classified the samples into peat (4), clay (16), sandy clay (28), fine sand (22), and medium coarse sand (1) and conserved them in glass containers for laboratory analyses. In order to contrast the soil samples with a low CEC material, we complemented the soil samples with one sample of pure silica sand with a grain diameter of $184 \mu \mathrm{m}$ (sample \#Sd184, see Table 1). Hence, we analyzed 72 samples in total.

\subsection{Complex conductivity measurements}

For the sample holders, we keep the samples in their buckets with a cap (Figure 6). Four equally-spaced non polarizing $\mathrm{Ag}-\mathrm{AgCl}_{2}$ electrodes (diameter $4 \mathrm{~mm} \times 1 \mathrm{~mm}$ ) are placed in the top of the sample holder with the cap. The interval between two consecutive electrodes is $2 \mathrm{~cm}$. For the first experiment (i.e., performed at the lowest salinity), the samples were first dried and then saturated under vacuum. To avoid the effect of the dissolved salts stemming from the natural soil salinity, the samples were stored were kept for the month in equilibrium with a degassed $\mathrm{NaCl}$ solution. Its salinity and conductivity have been controlled through the addition of dry $\mathrm{NaCl}$ salt to a certain volume of demineralized water and electrical conductivity measurements were made with a calibrated conductimeter. The core samples are 
saturated with the following $\mathrm{NaCl}$ brine solutions of following conductivities $0.031,0.526$, $1.15,5.7,14.7$, and $22 \mathrm{~S} \mathrm{~m}^{-1}$ (at $25^{\circ} \mathrm{C}$ ). The last conductivity corresponds to the conductivity of a solution at saturation in salt, so the highest conductivity reachable for a $\mathrm{NaCl}$ solution at $25^{\circ} \mathrm{C}$. All the conductivity data reported in this paper are corrected for the effect of temperature using $\sigma(T)=\sigma\left(T_{0}\right)\left[1+\alpha_{b}\left(T-T_{0}\right)\right]$ and reported at $25^{\circ} \mathrm{C}, T_{0}$ denotes the reference temperature $\left(T_{0}=25^{\circ} \mathrm{C}\right), T$ is the temperature of the solution, and $\alpha_{b} \approx 0.02 /{ }^{\circ} \mathrm{C}$ (Vinegar and Waxman [1984]). For the other pore water conductivities, the change of brine is done by diffusion by letting the samples in a big tank in which the solution is at the desired salinity. This solution is changed very regularly (e.g., Revil et al. [2013, 2014a]). Equilibrium was reached in several weeks. For a few selected core samples, the complex conductivity spectra were repeated over time and the batch was considered to have reached equilibrium when the conductivity spectra were not observed to change over time.

The resistance and phase shift are investigated at logarithmic intervals over the frequency range $0.1 \mathrm{~Hz}-45 \mathrm{kHz}$ by the four-terminal method with a high-precision impedance analyzer developed by Zimmermann et al. [2008] (see Figure 6). The imposed injection voltage is set to $1 \mathrm{~V}$. The measured phase is typically below $50 \mathrm{mrad}$, and most of the cases below $10 \mathrm{mrad}$ imposing the use of very rigorous procedures including (1) the use of 4 electrodes configuration, (2) electrodes with small phase errors and input impedances, (3) the minimization of potential electromagnetic couplings at high frequencies (i.e., minimizing metallic parts in the sample holders), (4) very stable electrodes for the low frequency measurements (i.e., no drifts), and (5) a correction procedure for equivalent circuit of the system without the core samples. The phase accuracy is typically around 0.1-0.2 mrad below $1 \mathrm{kHz}$ (Zimmermann et al. [2008], Revil and Skold [2011]). The total data acquisition time is around 10 minutes for each sample using 5 measurements per decade in frequency and 6 cycles per measurements (to obtain a standard deviation). 
An important point in the evaluation of the electrical conductivity is the determination of the geometrical factor (or cell constant) of the sample holder (e.g., Jougnot et al. [2010]). This factor is required to convert a resistance (or an impedance) to a resistivity (or complex resistivity). It accounts for the position of the electrodes, the boundary conditions, and possibly the conductivity of the material in the sample holder which affects the distribution of the current lines between the current electrodes A and B. In the present case, we use two distinct procedures to get this geometrical factor. The first procedure is based on using Comsol Multiphysics to solve numerically the Laplace equation for the electrical potential and considering the geometry of the sample holder and the position of the four electrodes AMNB (Figure 6). For materials with an electrical conductivity in the range $10^{-3} \mathrm{~S} \mathrm{~m}^{-1}$ to $1 \mathrm{~S}$ $\mathrm{m}^{-1}$, the geometrical constant was found to be $16.6 \pm 0.1 \mathrm{~m}^{-1}$. The second procedure was to fill the sample holder with brines of known conductivity (measured independently with a calibrated conductimeter) and measuring the resistance with our impedance meter. We found a geometrical factor of $16.5 \pm 0.5 \mathrm{~m}^{-1}$ independent of the conductivity (we used four brines in the range $0.01 \mathrm{~S} \mathrm{~m}^{-1}$ to $1 \mathrm{~S} \mathrm{~m}^{-1}$ ). In the following, we use a geometrical factor of $16.5 \mathrm{~m}^{-1}$ independent of the conductivity of the material in the sample holder to interpret the impedance measurements.

Typical spectra are shown in Figures 7 and 8. At high frequencies (typically above 200 to 1000 Hertz), we can observe the Maxwell-Wagner polarization. Below these frequencies, the complex conductivity response is thought to be dominated by the polarization of the electrical double layer shown in Figure 2.

\subsection{Porosity, cation exchange capacity, and specific surface area}

Regarding the bulk density of the core sample $\rho$ (in $\mathrm{kg} \mathrm{m}^{-3}$ ), we use the following equation $\rho=(1-\phi) \rho_{S}+\phi \rho_{w}$. where $\rho_{w}$ denotes the bulk density of the pore water $(1000 \mathrm{~kg}$ $\mathrm{m}^{-3}$ ). For silica and clay minerals, we use a bulk density of $2650 \mathrm{~kg} \mathrm{~m}^{-3}$. The density of the 
organic matter is $\sim 100 \mathrm{~kg} \mathrm{~m}^{-3}$ [Federer et al., 1993; Tremblay et al., 2002] but we do not explicitly account for the organic matter fraction in our bulk density estimates. As a result, this simplification contributes to uncertainty in our porosity estimates. In general, the density of the solid phase should be determined independently, particularly for other soils such as those rich in carbonates.

The cation exchange capacity data were obtained with the Hexammine cobalt (III) chloride method [Ciesielski et al., 1997]). In our case, the cation exchange capacity is determined as the capacity of removing amine from a $0.05 \mathrm{~N}$ Hexammine cobalt(III) Chloride solution. Hexammine cobalt(III) Chloride is characterized by a pronounced orange color. Because of sorption of the cobalt on clay minerals, the color of the solution gets weaker. By measuring the difference in strength of the color before and after contact with the sample, we can determine the CEC. The reduction in color is performed by absorbance measurements with a calibrated spectrophotometer (Bibby Scientific ${ }^{\mathrm{TM}}$ Jenway $^{\mathrm{TM}}$ 6320D). The CEC provided in Table 1 are expressed in meq/100 $\mathrm{g}$ of dry material (which is the traditional unit for this parameter) and can be converted in the international system of units using $1 \mathrm{meq} / 100$ $\mathrm{g}=963.20 \mathrm{C} \mathrm{kg}^{-1}$

The CEC methodology was tested with a smectite from the Clay Mineralogical Society (smectite SWy-2, Na-Montmorillonite from Wyoming, USA). We measured a CEC of $73.6 \mathrm{meq} / 100 \mathrm{~g}$ while the reported CEC is $75 \mathrm{meq} / 100 \mathrm{~g}$. The CEC methodology was revised to be applied to the clean sand (using a higher mass of grains and a reference solution with a lower concentration of Hexamine cobalt(III) Chloride). The result is reported in Table 1). The $\mathrm{CEC}$ is reported versus the clay content in Figure 9. We see a rough linear relationship between the two quantities. If we extrapolate this relationship to $100 \%$ clay content, we find that the CEC of the pure clay fraction is $\sim 100 \mathrm{meq} / 100 \mathrm{~g}$, i.e., close to the CEC of pure smectite. This indicates that the soil samples we used are very rich in smectite. 
Specific surface area measurements (relative to weight, i.e., in $\mathrm{m}^{2} \mathrm{~g}^{-1}$ ) were also performed using the Brunauer-Emmett-Teller (BET) method using the five points method [Brunauer et al., 1938]. The BET measurements were performed using the Autosorb iQ gas sorption system from Quantachrome Instruments. The core samples were prepared in 1 to $5 \mathrm{~g}$ of powder. The samples were degassed at $20^{\circ} \mathrm{C}$ for a minimum of 12 hours under a vacuum condition (Clausen and Fabricius [2000]). After degassing, the tube with evacuated samples was analyzed using liquid Nitrogen at $77 \mathrm{~K}$. As a given relative pressure is reached, some nitrogen sorbs on the sample. During adsorption, the relative pressure is systematically increased while recording the volume of $\mathrm{N}_{2}$ adsorbed $\left(\mathrm{cm}^{3} / \mathrm{g}\right)$ at each partial pressure. The underlying theory of the BET approach is used to fit the data and to determine the specific surface area of the core samples, which are reported in Table 1.

\subsection{Effects of temperature and saturation}

Few additional measurements were performed to check the effects of both temperature and saturation. For temperature, a sample was placed in a bag immersed in a temperaturecontrolled bath and the temperature was changed in the range $25-38^{\circ} \mathrm{C}$. For saturation, several samples were prepared from the same core and mixed with a prescribed amount of water and oil to reach the following set of water saturations $s_{w}=1.0,0.80,0.60,0.40$, and 0.20 .

\section{Results}

\subsection{Surface conductivity and formation factor}

The conductivity of a soil versus the pore water conductivity usually displays a linear portion at solution conductivities and non-linear portion at low solution conductivities [e.g., Shainberg et al., 1980]. An example of such a behavior is shown in Figure 10. The formation factor $F$ and the surface conductivity $\sigma_{S}$ (at a given frequency) are determined by plotting the in-phase conductivity versus the pore water conductivity (see Figures 11 and 12) and fitting 
the linear portion of the conductivity data using equation (5). The formation factors and surface conductivities are reported in Table 1. In Figure 13, we plot the formation factors versus the corresponding porosities. The dataset is fitted with an Archie's law for the full set of core samples. This Archie's law $F=a \phi^{-m}$ (applied at once to all the core samples together, $a$ and $m$ are purely empirical parameters) should not be misled with the Archie's law used individually for each core sample $F=\phi^{-m}$ where $m$ denotes the Archie's exponent for each core sample and no calibration factor $a$ is applied.

\subsection{Normalized chargeability versus quadrature conductivity}

We first investigate the relationship between the $\mathrm{PFE}=100 \mathrm{FE}$ and the phase over one decade (i.e., $D=10$, see Appendix A) and more explicitly between 10 Hertz and 100 Hertz avoiding the effect of the Maxwell-Wagner polarization at high frequencies and noise in the data below $1 \mathrm{~Hz}$. In this case the percentage frequency effect (PFE) is given by $\mathrm{PFE} \approx 0.1467 \varphi$ [Vinegar and Waxman, 1984] where the phase is here expressed in mrad. In Figure 14, we use all of the sample data to study if this relationship is obeyed for in phase conductivity measured between 10 and 100 Hertz and the phase measured at the geometric mean (32 Hertz). We see that there is a perfect agreement for most of the data with the relationship $\mathrm{PFE}=100 \mathrm{FE} \approx 0.1467 \varphi$. The data that are too far from the trend are considered to be problematic (either because of experimental errors or because Drakes's model does not apply) and are not considered further.

In order to test equation (12), we perform an additional test on our data using all the core samples. We compare in Figure 15, the normalized chargeability between 1 Hertz and 1 $\mathrm{kHz}$ and the quadrature conductivity determined at the geometric mean frequency of 32 Hertz. This normalized chargeability is defined as the difference in the in-phase conductivity 
between $1 \mathrm{kHz}$ and 1 Hertz. The data shown in Figure 15 exhibit linear trend with a slope $\alpha$ $=4.4$ consistent with the theoretical prediction.

In Figure 16, we compare the normalized chargeability now determined over the frequency range $1 \mathrm{Hertz}-10 \mathrm{kHz}$ (so 4 decades, $D=10^{4}$ ) with the quadrature conductivity at the geometric mean frequency of 100 Hertz. The data shown in Figure 16 exhibit a linear trend with a slope $\alpha=6.2$ consistent with the theoretical prediction for Drakes' model $\alpha=$ 5.9. In both cases, other data that are too far from the predicted trend are discarded for further analysis.

\subsection{Quadrature versus surface conductivities}

In Figure 17, we plot the quadrature conductivity versus the surface conductivity at the lowest salinity investigated in the present study $\left(\sim 0.03 \mathrm{~S} \mathrm{~m}^{-1}, \mathrm{NaCl}, 25^{\circ} \mathrm{C}\right)$. Same observations can be made at other frequencies. At this salinity, the conductivity of the soil samples is dominated by the surface conductivity as shown by Figures 10 to 12 .

In Figure 18, we use the surface conductivity determined using the full conductivity data set. We see that the trend displayed by the soil is consistent with other data sets. The soil samples investigated in the present paper are characterized by higher surface and quadrature conductivities than the core samples investigated in previous studies (see for instance Weller et al. [2013], Woodruff et al. [2014], Revil et al. [2014b], Revil et al. [2017a, b]). Figure 18 validates equation (16) in providing a mean value of the dimensionless number $R$, this value being valid for several data sets.

\subsection{Normalized chargeability and chargeability}

In Figures 19 and 20, we plot the normalized chargeability obtained at the lowest

salinity in this work versus the surface conductivity and the quadrature conductivity, respectively. Using these data and using equations (14) and (16), we have 


$$
\begin{aligned}
& -\left(\frac{\sigma^{\prime \prime}}{\sigma_{S}^{\infty}}\right)=\frac{R}{\alpha} \approx 7.1 \times 10^{-3}, \\
& \alpha \approx-\frac{M_{n}}{\sigma^{\prime \prime}}=8.1,
\end{aligned}
$$

and therefore $\mathrm{R} \approx 0.057$. From Table 1 , the mean value of the tortuosity of our core sample is $F \phi=4.5$. From Figure 21, the mobility of the counterions in the Stern layer is given by $\beta_{(+)}^{S} f=1.4 \times 10^{-9} \mathrm{~m}^{2} \mathrm{~s}^{-1} \mathrm{~V}^{-1}$. Using $\beta_{(+)}^{S}=1.9 \times 10^{-9} \mathrm{~m}^{2} \mathrm{~s}^{-1} \mathrm{~V}^{-1}$, we obtain $f=0.74$. In other words, $74 \%$ of the counterions are located or partitioned in the Stern layer. This is consistent with the values generally used in the dynamic Stern layer model at low salinities, especially for smectite-rich materials (Revil, 2013a).

\subsection{Influence of temperature}

In Figure 22a, we plot the in-phase and quadrature components of the complex conductivity as a function of temperature for the temperature range $25^{\circ} \mathrm{C}-38^{\circ} \mathrm{C}$ (at $100 \mathrm{Hertz}$, Sample BJ_J0811641, water conductivity at $\left.25^{\circ} \mathrm{C}, 0.048 \mathrm{~S} \mathrm{~m}^{-1} \mathrm{NaCl}\right)$. We found that $\alpha_{w} \approx \alpha_{S} \approx 0.020^{\circ} \mathrm{C}^{-1} \approx \alpha_{b}$. In Figure $22 \mathrm{~b}$, we see that at first approximation, the chargeability $M$ is independent of the temperature as predicted by the dynamic Stern layer model in the context of Drakes's model. Perhaps, the observed slight decrease with temperature rise may be due to the release of cations from the Stern to the pore water.

\subsection{Influence of saturation}

The influence of saturation at low salinity is shown in Figure 23. At low salinity (here for a pore water conductivity of $0.006 \mathrm{~S} \mathrm{~m}^{-1}$ at $25^{\circ} \mathrm{C}$ ), the in-phase conductivity is dominated by the surface conductivity and the saturation dependence of the conductivity of the soil is $s_{w}{ }^{n-1}$. The quadrature conductivity depends on saturation according to $s_{w}{ }^{p}$ with $p=n-1$ [Vinegar and Waxman, 1984; Revil, 2013]. The results shown in Figure 3 agree with this picture with $n \approx 2$ and $p \approx 0.9$. For instance in Figure 24, we plot the in-phase conductivity of 
sample BB (also a fine sand) with the water saturation. This allows determining directly the second Archie's exponent $n$ and we find $n \approx 1.9$, a value consistent with the previous values.

\section{Discussion}

Surface conductivity is an important ingredient in the interpretation of DC (Direct Current) resistivity data in hydrogeophysics. It is often neglected because it is difficult to independently measure surface conductivity under field conditions. The results of this study are in line with previous studies showing relationships between the surface conductivity, the quadrature conductivity, the normalized chargeability, the cation exchange capacity, and the specific surface area. The measured surface conductivities of our Holocene sediment samples was high compared to what has been reported from other studies. Therefore, in similar geological environments, it is recommended to take into account the effect of the surface conductivity in the interpretation of DC resistivity tomograms.

The formation factors that have been derived in our study are remarkably higher than the ones inferred in previous studies in the same study area (e.g., De Louw et al. [2011]). To some extent this can be explained by the effect of the surface conductivity, which has not been taken into account previously. However, application of equation (5) with the values obtained for the surface conductivity, formation factor, and DC resistivity data [De Louw et al., 2011] generally leads to a higher pore water conductivity than what has been observed in hydrochemical sampling data. Finding a relationship for these differences is beyond the scope of this study, and it is recommended to study this issue further in the future.

\section{Conclusion}

We have developed a large dataset of complex conductivity measurements of soils in order to test further the relationship between the normalized chargeability, the quadrature 
conductivity, and the surface conductivity, the cation exchange capacity, and the specific surface area. The relationship between the normalized chargeability and the quadrature conductivity can be derived from Drakes's model, which predicts very accurately the data. The second relationship between the quadrature conductivity and the surface conductivity is directly an output of the dynamic Stern layer model of polarization. The normalized chargeability is linearly related to the cation exchange capacity of the materials while the chargeability is independent of the cation exchange capacity. Therefore, in hydrogeophysics, for facies discrimination it is preferable to image the normalized chargeability rather than the chargeability. In addition, the model can be used to predict the effect of temperature and water content on the complex conductivity of soils.

Acknowledgments. The dataset is available from the corresponding author (A. Revil, at andre.revil@univ-smb.fr). It will be posted on ResearchGate. We thank John C. Troelsen (at DTU, Denmark) for the BET measurements and Damien Jougnot for his help for the computation of the geometrical factor. We warmly thank Egon Zimmermann for the construction of the impedance meter This research was part of the FRESHEM Zeeland research program, a project in which BGR is also involved. We thank the associate editor, Dr. S. Moysey, as well as the three referees (Drs. D. Ntarlagiannis, A. Weller, and an anonymous referee) for their very constructive reviews of this paper and their time. 


\section{Appendix A. Frequency effect versus phase}

The amplitude of the complex resistivity $\rho^{*}$ is related to the amplitude of the complex conductivity $\sigma^{*}$ by,

$$
\rho=\left|\rho^{*}\right|=\frac{1}{\left|\sigma^{*}\right|}=\frac{1}{\sqrt{\sigma^{\prime 2}+\sigma^{\prime 2}}} .
$$

and $\sigma^{*}=\sigma^{\prime}+i \sigma^{\prime \prime}$. The phase lag $\varphi$ is related to the in-phase and quadrature components of the complex conductivity by,

$$
\tan \varphi=\frac{\sigma^{\prime \prime}}{\sigma^{\prime}}
$$

(the phase is negative when the quadrature conductivity is negative). The frequency effect is defined differently in different papers. For instance we can find,

$$
\begin{aligned}
& \mathrm{FE}=\frac{\rho^{\prime}(\omega)-\rho^{\prime}(D \omega)}{\rho^{\prime}(\omega)}, \\
& \mathrm{FE}=\frac{\rho(\omega)-\rho(D \omega)}{\rho(D \omega)},
\end{aligned}
$$

in Vinegar and Waxman [1984] (their equation 8) and Börner [1992] (his equation 5), respectively. Since the phase is usually small and the conductivity is dominated by the inphase conductivity, we can also derive the expression used in the main text

$$
\mathrm{FE} \approx \frac{\sigma^{\prime}(D \omega)-\sigma^{\prime}(\omega)}{\sigma^{\prime}(D \omega)}
$$

i.e., we are just using the in-phase component of the complex conductivity at two frequencies. To obtain equation (A5), we have started with the expression by Vinegar and Waxman [1984], Equation (A3), and we have neglected the imaginary component of the complex resistivity. Following Van Voorhis et al. [1973], we can now relate the FE to the phase. Van Voorhis et al. [1973] started their analysis using Drake's complex resistivity model,

$$
\rho^{*}(\omega)=K\left(\omega_{\rho}+i \omega\right)^{-b}
$$


where $K$ is a constant, $b$ positive exponent linearly related to the chargeability $M$ [Van Voorhis et al., 1973], and $\omega_{\rho}(>0)$ a characteristic frequency. This parametric model provides usually a fairly good fit to experimental data in the frequency range 0.1 Hertz-100 Hertz (e.g., Börner [1992]). Experimental data shows that $b<<1$ [Van Voorhis et al., 1973, Börner, 1992]. Note that this model is also similar to the model of Jonscher [1981] $\sigma^{*}(\omega)=\sigma_{n}\left(i \omega_{n}\right)^{1-p}$ where $\sigma_{n}$ denotes the amplitude factor, $p$ is a frequency exponent, and $\omega_{n}$ the angular frequency normalized to $1 \mathrm{~s}^{-1}$ [Börner, 1992]. In order to determine the amplitude and the phase, we start with equation (A6),

$$
\rho^{*}(\omega)=K \exp \left[-b \ln \left(\omega_{\rho}+i \omega\right)\right]
$$

The log of a complex number $\ln (\alpha+i \beta)$ is given by:

$$
\ln (\alpha+i \beta)=\ln \left(\sqrt{\alpha^{2}+\beta^{2}}\right)+i\left(2 \tan ^{-1}\left(\frac{\beta}{\alpha+\sqrt{\alpha^{2}+\beta^{2}}}\right)+2 k \pi\right)
$$

When $k \in \square$ and only if $\alpha \geq 0$, and retaining the first determination (i.e., $k=0$ ), we can write:

$$
\ln (\alpha+i \beta)=\ln \left(\sqrt{\alpha^{2}+\beta^{2}}\right)+i \tan ^{-1}\left(\frac{\beta}{\alpha}\right)
$$

Applying equation (A9) to (A7) yields

$$
\begin{aligned}
& \rho^{*}(\omega)=K \exp \left[-b \ln \sqrt{\omega_{\rho}^{2}+\omega^{2}}-i b \tan ^{-1}\left(\frac{\omega}{\omega_{\rho}}\right)\right], \\
& \rho^{*}(\omega)=K\left(\omega_{\rho}^{2}+\omega^{2}\right)^{-\frac{b}{2}} \exp \left[-i b \tan ^{-1}\left(\frac{\omega}{\omega_{\rho}}\right)\right] .
\end{aligned}
$$

The complex resistivity can be expressed in terms of its amplitude and phase,

$$
\begin{aligned}
& \rho^{*}(\omega)=\left|\rho^{*}(\omega)\right| \exp [i \varphi], \\
& \rho=\left|\rho^{*}(\omega)\right|=K\left(\omega_{\rho}^{2}+\omega^{2}\right)^{-\frac{b}{2}},
\end{aligned}
$$




$$
\varphi=-b \tan ^{-1}\left(\frac{\omega}{\omega_{\rho}}\right) .
$$

respectively. In the limit $\omega>>\omega_{\rho}$ the phase is given by $b \approx-2 \varphi / \pi$. This is why the Drake's model is also called the constant phase model. Van Voorhis et al. [1973] start with a slightly different definition of the FE than given above,

$$
\mathrm{FE}=\frac{\rho(\omega)-\rho(D \omega)}{\rho(\omega)} .
$$

Now the frequency effect between $\omega$ and $D \omega$ is given by $\mathrm{FE}=1-D^{b}$. Using the expression $b \approx-2 \varphi / \pi$ derived above, we obtain,

$$
\begin{aligned}
& \mathrm{FE}=1-D^{-\frac{2}{\pi} \varphi}, \\
& 1-\mathrm{FE}=D^{-\frac{2}{\pi} \varphi}, \\
& \ln (1-\mathrm{FE})=\ln D^{-\frac{2}{\pi} \varphi} .
\end{aligned}
$$

Since FE is small (much smaller than unity, see Figure 14), we have

$$
\begin{gathered}
\mathrm{FE} \approx \ln \left\{D^{-\frac{2}{\pi} \varphi}\right\}=\ln \left\{\exp \left[\ln \left(D^{-\frac{2}{\pi} \varphi}\right)\right]\right\}, \\
\mathrm{FE} \approx-\frac{2}{\pi} \varphi \ln D .
\end{gathered}
$$

Equation (A20) corresponds to the equation used in the main text. Shuey and Johnson [1973] obtained exactly the same expression based on a very different complex resistivity model. This could mean that equation (A20) could be quite general but we end up not being able to derive a general proof for the validity of this equation. 


\section{References}

Abdulsamad, F., (2017), Polarisation provoquée: expérimentation, modélisation, et applications géophysiques, $\mathrm{PhD}$ thesis, UPMC, $159 \mathrm{pp}$.

Ahmadi, A., M.-R. Neyshabouri, H. Rouhipour, and H. Asadi (2011), Fractal dimension of soil aggregates as an index of soil erodibility, Journal of Hydrology, 400(3-4), 305-311.

Archie, G. E. (1942), The electrical resistivity log as an aid in determining some reservoir characteristics, Trans. AIME, 146, 54-62.

Bernabé, Y., M. Zamora, M. Li, A. Maineult, and Y. B. Tang (2011), Pore connectivity, permeability, and electrical formation factor: A new model and comparison to experimental data, J. Geophys. Res., 116, B11204, doi:10.1029/2011JB008543.

Bernabé, Y., and A. Revil (1995), Pore-scale heterogeneity, energy dissipation and the transport properties of rocks, Geophysical Research Letters, 22(12), 1529-1552.

Binley, A., Slater, L.D., Fukes, M. and Cassiani, G. (2005), Relationship between spectral induced polarization and hydraulic properties of saturated and unsaturated sandstone, Water Res. Res. 41, w12417, doi:10.1029/2005WR004202.

Binley A., S. S. Hubbard, J. A. Huisman, A. Revil, D. A. Robinson, K. Singha, and L. D. Slater (2015), The emergence of hydrogeophysics for improved understanding of subsurface processes over multiple scales, Water Resources Research, 51, 3837-3866, doi: 10.1002/2015WR017016.

Bohren, C. F, (2010), What did Kramers and Kronig do and how did they do it? Eur. J. Phys., 31, 573-577, doi:10.1088/0143-0807/31/3/014.

Börner, F.D. (1992), Complex conductivity measurements of reservoir properties, Proc Third European Core Analysis Symposium, Paris, 359-386.

Brunauer, S., P.H., Emmett, and E., Teller (1938), Adsorption of gasses in multimolecular layers, J. Am. Chem. Soc., 60(2), 309-319. doi: 10.1021/ja01269a023. 
Chen, J., S. S. Hubbard, and K. H. Williams (2013), Data-driven approach to identify fieldscale biogeochemical transitions using geochemical and geophysical data and hidden Markov models: Development and application at a uranium-contaminated aquifer, Water Resour. Res., 49, doi:10.1002/wrcr.20524.

Ciesielski, H., T., Sterckeman, M., Santerne, and J.P., Willery (1997), Determination of cation exchange capacity and exchangeable cations in soils by means of cobalt hexamine trichloride. Effects of experimental conditions, Agronomie, EDP Sciences, $17(1), 1-7$

Clausen, L., and I. Fabricius (2000), BET Measurements: outgassing of mineral, Journal of Colloid and Interface Science 227, 7-15, doi:10.1006/jcis.2000.6880.

Cole, K. S., and R. H. Cole (1941), Dispersion and absorption in dielectrics. I. Alternating current characteristics, Journal of Chemical Physics, 9, 341-351.

Flores Orozco A., A. Kemna, C. Oberdörster, L. Zschornack, C. Leven, P. Dietrich and H. Weiss (2012), Delineation of subsurface hydrocarbon contamination at a former hydrogenation plant using spectral induced polarization imaging, Journal of Contaminant Hydrology, 136-137, 131-144.

De Louw, P.G.B., S., Eeman, B., Siemon, B.R., Voortman, J., Gunnink, S.E., Van Baaren, and G.H.P. Oude Essink (2011), Shallow rainwater lenses in deltaic areas with saline seepage, Hydrology and Earth System Sciences, 15, 3659-3678.

Federer, C. A., D. E. Turcotte, and C. T. Smith, (1993), The organic fraction-bulk density relationship and the expression of nutrient content in forest soils, Can. J. For. Res., 23, 1026-1032.

Florsch, N., A. Revil, and C. Camerlynck (2014), Inversion of generalized relaxation time distributions with optimized damping parameter, Journal of Applied Geophysics, 109, 119-132, doi: 10/1016/j.jappgeo.2014.07.013. 
Friedman, S. P., (2005), Soil properties influencing apparent electrical conductivity: a review, Computers and Electronics in Agriculture, 46, 45-70.

Fuoss R.M., and J.G. Kirkwood (1941), Electrical properties of solids. VIII. dipole moments in polyvinyl chloride-diphenyl systems, Am. Chem. Soc., 63, 385-394, doi: $10.1021 / \mathrm{ja} 01847 \mathrm{a} 013$.

Grimm, R.E., D.E. Stillman (2015), Field test of detection and characterisation of subsurface ice using broadband spectral-induced polarization, Permafrost and Periglac. Process. $26,28-38$.

Hao, N., S.M.J. Moysey, B. A., Powell, and D. Ntarlagiannis (2016), Comparison of the surface ion density of silica gel evaluated via spectral induced polarization versus acidbase titration, Journal of Applied Geophysics, 135, 427-435, doi: 10.1016/j.jappgeo.2016.01.014.

Hyslip, J. P., and L. E. Vallejo (1997), Fractal analysis of the roughness and size distribution of granular materials, Eng. Geol., 48(3,4), 231- 244.

Johnson, D. L., T. J. Plona, and H. Kojima, (1986), Probing porous media with 1st sound, 2nd sound, 4th sound and 3rd sound: in Physics and Chemistry of Porous Media, II, edited by R. Jayanth, J. Banavar, and K. W. Winkler, 243-277, AIP, New York.

Johnson T. C., R. J. Versteeg, A. Ward, F. D. Day-Lewis, and A. Revil (2010), Improved hydrogeophysical characterization and monitoring through high performance electrical geophysical modeling and inversion, Geophysics, 75(4), WA27-WA41, doi: 10.1190/1.3475513.

Jonscher, A.K. (1981), A new understanding of the dielectric relaxation of solids. Journal of Material Sciences, 16, 2037-2060. 
Joseph, S., M., Ingham, and G., Gouws (2015), Spectral Induced Polarization Measurements on New Zealand Sands - Dependence on Fluid Conductivity, Near-surface Geophysics $13,169-177$.

Jougnot D., A. Ghorbani, A. Revil, P. Leroy, and P. Cosenza (2010), Spectral Induced Polarization of partially saturated clay-rocks: A mechanistic approach, Geophysical Journal International, 180(1), 210-224, doi: 10.1111/j.1365-246X.2009.04426.x.

Kemna, A., A., Binley, G., Cassiani, E., Niederleithinger, A., Revil, L., Slater, K.H., Williams, A., Flores Orozco, F.-H., Haegel, A., Hördt, S., Kruschwitz, V., Leroux, K. Titov, and E.,Zimmermann (2012), An overview of the spectral induced polarization method for near-surface applications, Near Surface Geophysics, 10, 453-468, doi:10.3997/1873-0604.2012027.

Kramers H. A. (1927), La diffusion de la lumiére par les atomes, Atti del Congresso Internazionale dei Fisici, Como-Pavia-Roma, Vol. 2 (Bologna: Nicola Zanichelli) pp $545-57$.

Kronig R. de L. (1926), On the theory of dispersion of X-rays J. Opt. Soc. Am. Rev. Sci. Instrum. 12 547-57.

Kronig R. de L. (1942), Algemeene theorie der di“electrische en magnetische verliezen (General theory of dielectric and magnetic losses) Ned. Tijdschr. Natuurkd. 9 402-9.

Mansoor, N., and L. Slater, (2007), On the relationship between iron concentration and induced polarization in marsh soils, Geophysics, 72(1), A1-A5, doi: 10.1190/1.2374853.

Mao, D., and A. Revil, (2016), Induced polarization response of porous media with metallic particles. - Part 3. A new approach to time-domain induced polarization tomography, Geophysics, 81(4), D345-D357, doi: 10.1190/geo2015-0283.1.

Mao, D., A., Revil, and J. Hinton (2016), Induced polarization response of porous media with metallic particles. - Part 4. Detection of metallic and non-metallic targets in time 
domain induced polarization tomography, Geophysics, 81(4), D359-D375, doi: 10.1190/geo2015-0480.1.

Mewafy F. M., D. D. Werkema, E. A. Atekwana, L. D. Slater, G. Abdel Aal, A. Revil, and D. Ntarlagiannis (2013), Evidence that bio-metallic mineral precipitation enhances the complex conductivity response at a hydrocarbon contaminated site, Journal of Applied Geophysics, 98, 113-123, doi: 10.1016/j.jappgeo.2013.08.011.

Niu Q., A. Revil, and M. Saidian, (2016), Salinity dependence of the complex surface conductivity of the Portland sandstone, Geophysics, 81(2), D125-D140, doi: 10.1190/GEO2015-0426.1.

Nordsiek, S., E., Diamantopoulos, A. Hördt, and W. Durner (2015), Relationships between soil hydraulic parameters and induced polarization spectra, Near Surface Geophysics, 14, 23-37, doi: 10.3997/1873-0604.2015048.

Okay G., P. Cosenza, A. Ghorbani, C. Camerlynck, J. Cabrera, N. Florsch, and A. Revil (2013), Characterization of macroscopic heterogeneities in clay-rocks using induced polarization: Field tests at the experimental underground research laboratory of Tournemire (Aveyron, France), Geophysical Prospecting, 61, 134-152, doi: 10.1111/j.1365-2478.2012.01054.x.

Okay, G., P. Leroy, A. Ghorbani, P. Cosenza, C. Camerlynck, J. Cabrera, N. Florsch, and A. Revil (2014), Spectral induced polarization of clay-sand mixtures. Experiments and modeling, Geophysics, 79, 6, E353-E375, doi: 10.1190/GEO2013-0347.1,.

Revil, A., L.M., Cathles, S. Losh, and J.A., Nunn (1998), Electrical conductivity in shaly sands with geophysical applications, Journal of Geophysical Research, 103(B10), 23,925-23,936, 1998. 
Revil, A. and N. Florsch (2010), Determination of permeability from spectral induced polarization data in granular media, Geophys. J. Int., 181, 1480-1498, doi: 10.1111/j.1365-246X.2010.04573.x.

Revil A., and M. Skold (2011), Salinity dependence of spectral induced polarization in sands and sandstones, Geophysical Journal International, 187, 813-824, doi: 10.1111/j.1365246X.2011.05181.x.

Revil, A., K. Koch, and K. Holliger (2012), Is it the grain size or the characteristic pore size that controls the induced polarization relaxation time of clean sands and sandstones?, Water Resources Research, 48, W05602, doi:10.1029/2011WR011561.

Revil, A. (2013a) Effective conductivity and permittivity of unsaturated porous materials in the frequency range $1 \mathrm{mHz}-1 \mathrm{GHz}$, Water Resources Research, 49, 306-327, doi:10.1029/2012WR012700.

Revil, A. (2013b), On charge accumulations in heterogeneous porous materials under the influence of an electrical field, Geophysics, 78(4), D271-D291, doi: 10.1190/GEO20120503.1.

Revil, A., J.D., Eppehimer, M., Skold, M., Karaoulis, L., Godinez, and M. Prasad (2013), Low-frequency complex conductivity of sandy and clayey materials, Journal of Colloid and Interface Science, 398, 193-209.

Revil A., N. Florsch, and C. Camerlynck, (2014a), Spectral induced polarization porosimetry, Geophysical Journal International, 198, 1016-1033, doi: 10.1093/gji/ggu180.

Revil, A., P. Kessouri, and C. Torres-Verdín (2014b), Electrical conductivity, induced polarization, and permeability of the Fontainebleau sandstone, Geophysics, 79(5), D301-D318, doi: 10.1190/GEO2014-0036.1. 
Revil A., N. Florsch, and D. Mao (2015a), Induced polarization response of porous media with metallic particles - Part 1: A theory for disseminated semiconductors, Geophysics, 80(5), D525-D538, doi: 10.1190/GEO2014-0577.1.

Revil A., G. Z. Abdel Aal, E.A. Atekwana, D. Mao, and N. Florsch (2015b), Induced polarization response of porous media with metallic particles - Part 2. Comparison with a broad database of experimental data, Geophysics, 80(5), D539-D552, doi: 10.1190/GEO2014-0578.1.

Revil, A., A., Binley, L., Mejus, and P., Kessouri, (2015c), Predicting permeability from the characteristic relaxation time and intrinsic formation factor of complex conductivity spectra, Water Resour. Res., 51, doi:10.1002/2015WR017074.

Revil A., M., Le Breton, Q., Niu, E., Wallin, E., Haskins, and D.M., Thomas, (2017a), Induced polarization of volcanic rocks. 1. Surface versus quadrature conductivity, Geophysical Journal International, 208, 826-844, doi: 10.1093/gji/ggw444.

Revil A., M., Le Breton, Q., Niu, E., Wallin, E., Haskins, and D.M., Thomas, 2017b, Induced polarization of volcanic rocks. 2. Influence of pore size and permeability, Geophysical Journal International, 208, 814-825 doi: 10.1093/gji/ggw382.

Saidi, D., (2012), Importance and Role of Cation Exchange Capacity on the Physicals Properties of the Cheliff Saline Soils (Algeria), Procedia Engineering, 33, 435-449.

Schmutz, M., A. Blondel, and A. Revil (2012), Saturation dependence of the quadrature conductivity of oil-bearing sands, Geophysical Research Letters, 39, L03402, doi:10.1029/2011GL050474.

Schwartz, N. and A. Furman (2012), Spectral induced polarization signature of soil contaminated by organic pollutant: Experiment and modeling, J. Geophys. Res., 117, doi:10.1029/2012JB009543. 
Sen, P. N., C. Scala, and M. H. Cohen (1981), Self-similar model for sedimentary rocks with application to the dielectric constant of fused glass beads, Geophysics, 46, 781-795.

Shainberg, I., J.D., Rhoades, and R.J., Prather, (1980), Effect of ESP, cation exchange capacity, and soil solution concentration on soil electrical conductivity, Soil Sci. Soc. Am.J., 44, 469-473.

Shuey, R. T., and M., Johnson, (1973), On the phenomenology of electrical relaxation in rocks, Geophysics, 38, 37-48. doi: 10.1190/1.1440331.

Slater L. D. and D. R. Glaser, (2003) Controls on induced polarization in sandy unconsolidated sediments and application to aquifer characterization, Geophysics, 68(5), 1547-1558, doi: 10.1190/1.1620628.

Sogade J. A., F., Scira-Scappuzzo Y., Vichabian W., Shi W.Rodi, D. P., Lesmes F. Dale Morgan (2006), Induced-polarization detection and mapping of contaminant plumes, Geophysics, 71(3), B75-B84.

Stafleu, J., D.M., Maljers, J.L., Gunnink, A., Menkovic, and F.S. Busschers (2011), 3D modelling of the shallow subsurface of Zeeland, the Netherlands, Netherlands Journal of Geosciences, 90(4), 293-310.

Tremblay, S., R., Ouimet, and D., Houle, 2002. Prediction of organic carbon content in upland forest soils of Quebec, Canada. Can. J. For. Res., 32, 1-12.

Van Voorhis, G. D., P. H., Nelson, and T. L. Drake, (1973), Complex resistivity spectra of porphyry copper mineralization, Geophysics, 38(1), 49-60. doi: 10.1190/1.1440333.

Vaudelet P., Revil A., Schmutz M., Franceschi M., Bégassat P. (2011a), Induced polarization signature of the presence of copper in saturated sands, Water Resources Research, 47, W02526. 
Vaudelet P., Revil, A., Schmutz M., Franceschi M., Bégassat P. (2011b), Changes in induced polarization associated with the sorption of sodium, lead, and zinc on silica sands, Journal of Colloid and Interface Science, 360, 739-752.

Vinegar, H.J., and M.H., Waxman (1984), Induced polarization of shaly sands, Geophysics, $49,1267-1287$.

Waxman, M. H., and L. J. M. Smits (1968), Electrical conductivities in oil bearing shaly sands, SPE Journal, 8, 107-122.

Weller, A., S. Nordsiek, and W. Debschütz (2010), Estimating permeability of sandstone samples by nuclear magnetic resonance and spectral-induced polarization, Geophysics, 75(6), E215-E226, doi: 10.1190/1.3507304.

Weller, A., and L. Slater (2012), Salinity dependence of complex conductivity of unconsolidated and consolidated materials: Comparisons with electrical double layer models, Geophysics, 77(5), D185-D198, doi: 10.1190/geo2012-0030.1.

Weller, A., L. Slater, and S. Nordsiek, (2013), On the relationship between induced polarization and surface conductivity: Implications for petrophysical interpretation of electrical measurements, Geophysics, 78(5), D315-D325, doi: 10.1190/GEO20130076.1.

Woodruff W. F., A. Revil, and C. Torres-Verdín (2014), Laboratory determination of the complex conductivity tensor of unconventional anisotropic shales, Geophysics, 79(5), E183-E200, doi: 10.1190/GEO2013-0367.1.

Zimmermann, E., A., Kemna, J., Berwix, W., Glaas, H., Munch, and J., Huisman, (2008), A high-accuracy impedance spectrometer for measuring sediments with low polarizability, Measurement Science and Technology, 19(10), 105603. 


\section{Tables.}

Table 1. The formation factor and the surface conductivity are determined at the following pore water conductivities $0.031,0.53,1.15,5.7,14.7$, and $22 \mathrm{~S} \mathrm{~m}^{-1}$. The following parameters $\phi, \sigma_{S}, S_{p}$, and CEC denote the porosity, the surface conductivity, the specific surface area, and the cation exchange capacity, respectively. The following codes are used for the type of soil: $\mathrm{K}=$ clay, $\mathrm{KZ}=$ sandy clay, $\mathrm{V}=$ peat, $\mathrm{ZF}$ = fine sand, and $\mathrm{ZM}$ is medium coarse sand, $\mathrm{SS}$ : pure silica sand. ID is the code name of the samples. The quadrature conductivity is given at 1 $\mathrm{kHz}$. The CEC is reported in meq/100 g with $1 \mathrm{meq} / 100 \mathrm{~g}=1 \mathrm{cMol} \mathrm{kg}^{-1}=963.2 \mathrm{C} \mathrm{kg}^{-1}$ and the specific surface area $S_{s p}$ (measured with the BET method) is reported in $\mathrm{m}^{2} \mathrm{~g}^{-1} . M_{n}$ is determined at a pore water conductivity of $0.031 \mathrm{~S} \mathrm{~m}^{-1}$ between $0.1 \mathrm{Hertz}$ and $10 \mathrm{kHz}$. For the clean sand (\#Sd184), the normalized chargeability and the quadrature conductivity (at $20 \mathrm{~Hz}$, peak frequency) was obtained at a pore water conductivity of $0.1 \mathrm{~S} \mathrm{~m}^{-1} \mathrm{NaCl}$, and the CEC is an average of 5 measurements.

\begin{tabular}{|c|c|c|c|c|c|c|c|c|}
\hline ID & Type & $\begin{array}{l}F \\
(-)\end{array}$ & $\begin{array}{c}\sigma_{S} \\
(\mathrm{~S} / \mathrm{m})\end{array}$ & $\begin{array}{c}\phi \\
(-)\end{array}$ & $\begin{array}{c}\sigma^{\prime \prime} \\
\left(S \mathrm{~m}^{-1}\right)\end{array}$ & $\begin{array}{c}\text { CEC } \\
\text { (meq/100 g) }\end{array}$ & $\begin{array}{c}S_{p} \\
\left(\mathrm{~m}^{2} \mathrm{~g}^{-1}\right)\end{array}$ & $\begin{array}{c}M_{n} \\
\left(\mathrm{~S} \mathrm{~m}^{-1}\right)\end{array}$ \\
\hline AA & K & 5.3 & 0.40 & 0.730 & 0.003755 & 19.8 & 12.0 & 0.01378 \\
\hline$A B$ & ZF & 6.3 & 0.23 & 0.541 & 0.00087 & 7.10 & 6.52 & 0.001973 \\
\hline$A C$ & V & 4.0 & 0.37 & 0.941 & 0.00346 & 39.3 & 1.60 & 0.01420 \\
\hline$A D$ & $K Z$ & 6.17 & 0.39 & 0.691 & 0.002774 & 90.3 & 6.84 & 0.01117 \\
\hline $\mathrm{AE}$ & $K Z$ & 7.83 & 0.33 & 0.522 & 0.00139 & 19.1 & 10.23 & 0.005385 \\
\hline $\mathrm{AF}$ & K & 6.34 & 0.54 & 0.642 & 0.00295 & 17.6 & 19.35 & 0.009959 \\
\hline AG & $K Z$ & 11.0 & 0.34 & 0.487 & 0.000709 & 9.40 & 1.80 & 0.001708 \\
\hline $\mathrm{AH}$ & K & 9.1 & 0.34 & 0.486 & 0.002323 & 16.9 & 10.76 & 0.007969 \\
\hline $\mathrm{Al}$ & ZF & 11.4 & 0.29 & 0.498 & 0.000768 & 3.90 & 2.43 & 0.002055 \\
\hline AJ & $\mathrm{ZF}$ & 10.8 & 0.30 & 0.442 & 0.000672 & 3.40 & 3.94 & 0.001564 \\
\hline AK & $K Z$ & 8.8 & 0.32 & 0.549 & 0.002659 & 4.70 & 3.85 & 0.007869 \\
\hline AM & K & 5.32 & 0.49 & 0.722 & 0.004963 & 13.7 & 9.55 & 0.01952 \\
\hline AN & $K Z$ & 9.02 & 0.35 & 0.569 & 0.001473 & 4.10 & 3.62 & 0.00451 \\
\hline $\mathrm{AO}$ & $K Z$ & 10.23 & 0.31 & 0.453 & 0.001021 & 3.80 & 3.41 & 0.003025 \\
\hline $\mathrm{AP}$ & $K Z$ & 8.77 & 0.42 & 0.537 & 0.052054 & 9.50 & 7.99 & \\
\hline$A R$ & $K Z$ & 7.03 & 0.54 & 0.596 & 0.002076 & 11.8 & 9.03 & 0.007931 \\
\hline AS & ZF & 11.2 & 0.19 & 0.593 & 0.000368 & 0.900 & 0.35 & 0.0001673 \\
\hline AT & ZF & 9.4 & 0.20 & 0.495 & 0.000746 & 3.30 & 3.71 & 0.0007966 \\
\hline$A U$ & ZF & 11.0 & 0.21 & 0.543 & 0.000585 & 3.00 & 1.80 & 0.0008577 \\
\hline AV & ZF & 9.81 & 0.17 & 0.497 & 0.000419 & 1.70 & 0.187 & 0.0002919 \\
\hline AW & ZF & 10.75 & 0.18 & 0.555 & 0.000349 & 1.40 & 0.51 & 0.0004455 \\
\hline$A X$ & ZF & 10.98 & 0.24 & 0.418 & 0.000967 & 7.50 & 4.91 & 0.002469 \\
\hline AY & $\mathrm{ZF}$ & 10.18 & 0.19 & 0.513 & 0.000572 & 1.90 & 2.18 & 0.001180 \\
\hline$A Z$ & $K Z$ & 6.33 & 0.39 & 0.611 & 0.003214 & 16.0 & 14.61 & 0.012294 \\
\hline BA & ZF & 9.52 & 0.20 & 0.482 & 0.000555 & 2.00 & 1.92 & 0.001057 \\
\hline BB & ZF & 10.15 & 0.21 & 0.422 & 0.001186 & 7.00 & 7.86 & 0.004496 \\
\hline$B C$ & ZF & 8.87 & 0.22 & 0.491 & 0.000655 & 1.90 & 1.67 & 0.001526 \\
\hline BD & $\mathrm{ZF}$ & 8.69 & 0.23 & 0.542 & 0.001195 & 9.10 & 4.12 & 0.003382 \\
\hline $\mathrm{BE}$ & ZF & 11.28 & 0.30 & 0.487 & 0.000603 & 1.70 & 1.97 & 0.001360 \\
\hline $\mathrm{BF}$ & $K Z$ & 6.3 & 0.34 & 0.589 & 0.004337 & 16.8 & 7.9 & 0.008766 \\
\hline BG & K & 5.4 & 0.39 & 0.690 & 0.120592 & 14.2 & 14.6 & \\
\hline $\mathrm{BH}$ & $K Z$ & 9.4 & 0.37 & 0.443 & 0.003272 & 19.9 & 36.6 & 0.01030 \\
\hline BI & $\mathrm{KZ}$ & 4.75 & 0.16 & 0.638 & 0.00365 & 12.5 & 9.54 & 0.01112 \\
\hline
\end{tabular}




\begin{tabular}{|c|c|c|c|c|c|c|c|c|}
\hline BJ & KZ & 7.28 & 0.27 & 0.556 & 0.002161 & 3.60 & 9.5 & 0.008675 \\
\hline BK & KZ & 6.69 & 0.37 & 0.579 & 0.270767 & 12.5 & 8.8 & \\
\hline $\mathrm{BL}$ & $\mathrm{ZF}$ & 6.32 & 0.36 & 0.591 & 0.00173 & 3.60 & 7.0 & 0.005578 \\
\hline $\mathrm{BM}$ & KZ & 5.84 & 0.71 & 0.687 & 0.005476 & 13.6 & 22.9 & 0.014649 \\
\hline $\mathrm{BN}$ & $K Z$ & 8.04 & 0.43 & 0.526 & 0.009165 & 25.1 & 39.5 & 0.034022 \\
\hline BO & ZF & 5.68 & 0.39 & 0.619 & 0.003556 & 11.2 & 13.28 & 0.011060 \\
\hline $\mathrm{BP}$ & KZ & 6.97 & 0.53 & 0.590 & 0.001096 & 14.0 & 11.5 & \\
\hline$B Q$ & $\mathrm{ZF}$ & 9.3 & 0.42 & 0.466 & 0.003719 & 6.00 & 5.97 & 0.008123 \\
\hline BR & v & 3.9 & 0.38 & 0.927 & 0.003273 & 54.4 & 0.403 & 0.013473 \\
\hline BS & KZ & 8.4 & 0.33 & 0.494 & 0.003729 & 6.80 & 5.86 & 0.010003 \\
\hline BT & KZ & 5.9 & 0.40 & 0.666 & 0.001439 & 41.2 & 8.68 & 0.002899 \\
\hline $\mathrm{BU}$ & KZ & 8.2 & 0.21 & 0.410 & 0.001496 & 12.2 & 16.0 & 0.004577 \\
\hline BV & KZ & 8.8 & 0.50 & 0.442 & 0.001908 & 23.1 & 33.4 & 0.006894 \\
\hline BW & K & 7.5 & 0.41 & 0.533 & 1.126956 & 14.7 & 15.6 & \\
\hline$B X$ & K & 8.6 & 0.41 & 0.528 & - & 12.7 & 12.9 & \\
\hline BY & KZ & 8.3 & 0.37 & 0.508 & - & 12.5 & 16.05 & \\
\hline$B Z$ & K & 7.0 & 0.23 & 0.539 & 0.00296 & 12.9 & 10.5 & 0.01130 \\
\hline CA & K & 6.5 & 0.60 & 0.58 & 0.348636 & 13.4 & 15.0 & \\
\hline $\mathrm{CB}$ & KZ & 6.5 & 0.62 & 0.605 & 0.001569 & 12.0 & 17.16 & 0.00433 \\
\hline $\mathrm{CC}$ & KZ & 8.1 & 0.24 & 0.537 & 0.007913 & 24.7 & 10.0 & 0.02069 \\
\hline$C D$ & KZ & 9.1 & 0.45 & 0.454 & 0.008023 & 6.50 & 8.7 & 0.02324 \\
\hline $\mathrm{CE}$ & K & 6.7 & 0.27 & 0.568 & 0.002321 & 14.9 & 13.6 & 0.01856 \\
\hline CF & KZ & 6.5 & 0.34 & 0.636 & 0.000898 & 21.2 & 15.87 & 0.008728 \\
\hline CG & K & 4.8 & 0.62 & 0.784 & 0.003642 & 18.6 & 17.63 & 0.002066 \\
\hline $\mathrm{CH}$ & $K Z$ & 7.4 & 0.73 & 0.579 & 0.002245 & 16.0 & 3.30 & 0.01542 \\
\hline $\mathrm{Cl}$ & V & 8.5 & 0.35 & 0.454 & 0.001511 & 9.40 & 0.696 & 0.009177 \\
\hline CJ & ZF & 11 & 0.30 & 0.357 & - & 2.10 & 0.503 & 0.005117 \\
\hline CK & $Z M$ & 12.6 & 0.26 & 0.424 & 0.000819 & 2.90 & 0.48 & \\
\hline $\mathrm{CL}$ & $Z F$ & 14.2 & 0.23 & 0.346 & 0.004246 & 1.90 & 2.05 & 0.001751 \\
\hline $\mathrm{CM}$ & $K Z$ & 7.9 & 0.71 & 0.577 & - & 18.0 & 12.1 & 0.010447 \\
\hline $\mathrm{CN}$ & K & 6.1 & 0.38 & 0.578 & 0.003484 & 15.3 & 16.3 & 0.001333 \\
\hline $\mathrm{CO}$ & K & 7.7 & 0.53 & 0.497 & - & 14.8 & 14.4 & 0.012537 \\
\hline $\mathrm{CP}$ & V & 3.8 & 0.59 & 0.959 & 0.004004 & 26.6 & 0.39 & \\
\hline $\mathrm{CR}$ & $K$ & 7.3 & 0.54 & 0.606 & 0.003753 & 14.1 & 15.90 & 0.03283 \\
\hline CS & K & 8.3 & 0.37 & 0.465 & 0.003127 & 6.50 & 4.49 & 0.01306 \\
\hline CT & V & 3.97 & 0.45 & 0.968 & 0.002465 & 9.60 & 0.326 & 0.01037 \\
\hline CV & $\mathrm{ZF}$ & 10.4 & 0.28 & 0.422 & 0.00111 & 3.50 & 2.89 & 0.003900 \\
\hline CW & K & 8.37 & 0.30 & 0.463 & 0.001925 & 18.8 & 42.2 & 0.007671 \\
\hline$C X$ & $\mathrm{ZF}$ & 12 & 0.28 & 0.455 & - & & 0.871 & \\
\hline Sd184 & SS & 3.6 & 0.006 & 0.387 & $2 \times 10^{-5}$ & 0.096 & & 0.00009 \\
\hline
\end{tabular}




\section{Figures}

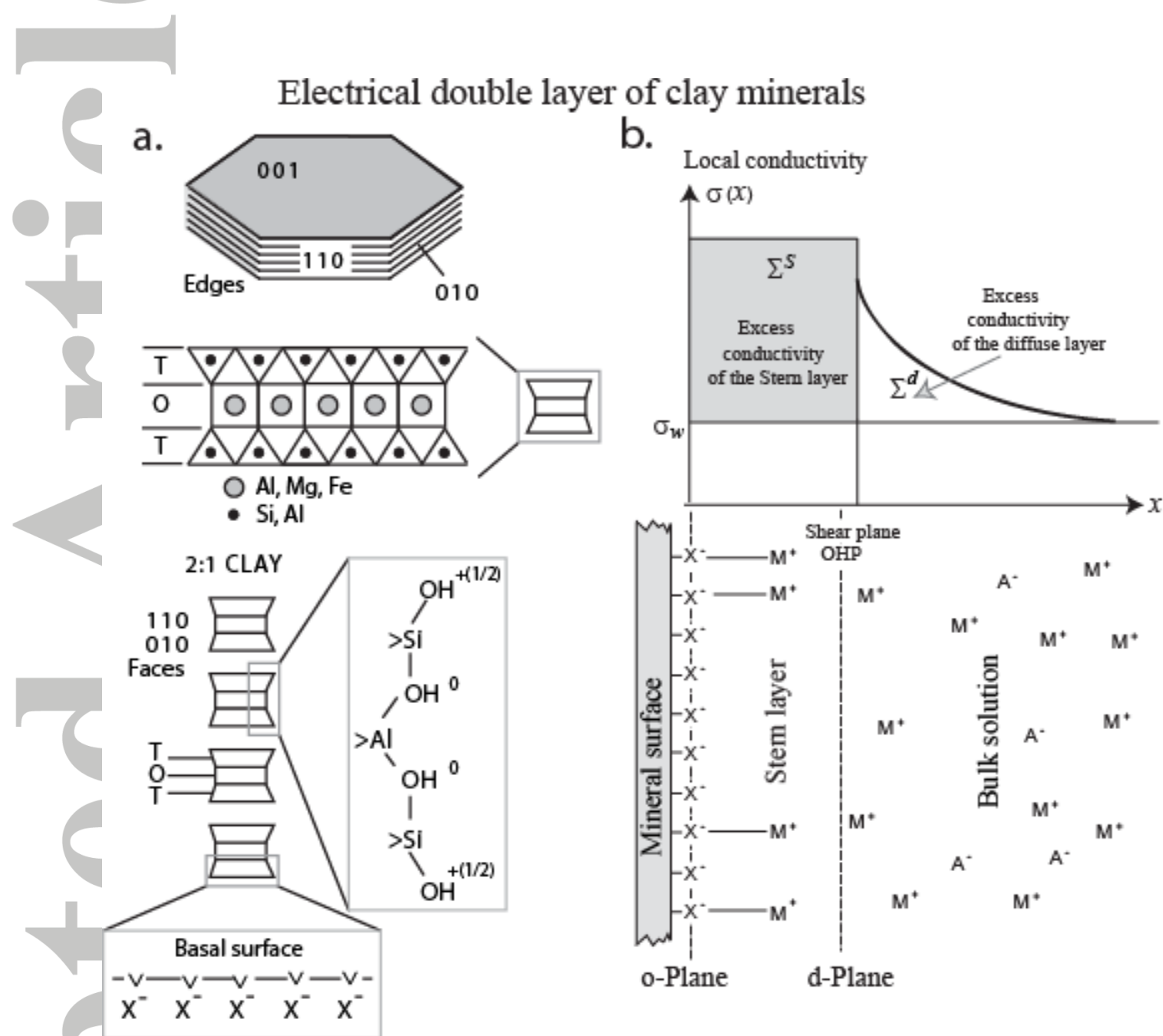

Figure 1. Nature of the electrical double layer in clay minerals. a. Clay minerals are characterized by a $\mathrm{pH}$-dependent charge on the edge of their particles and, for some of them like smectite, a permanent charge associated with isomorphic substitutions in their crystalline framework. b. The effective charge density is counterbalanced by ions in the Stern and diffuse layers. This gives rise to two excess conductivities defined as the integral over the distance of the difference between the local conductivity $\sigma(x)$ and the conductivity of the pore water $\sigma_{w}$. The surface conductivities $\Sigma^{S}$ and $\Sigma^{d}$ correspond to the contributions associated with the Stern and diffuse layers, respectively.

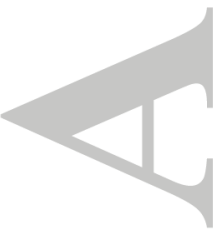


a. $t=0^{+}$

\section{$\mathrm{E}_{0}$}

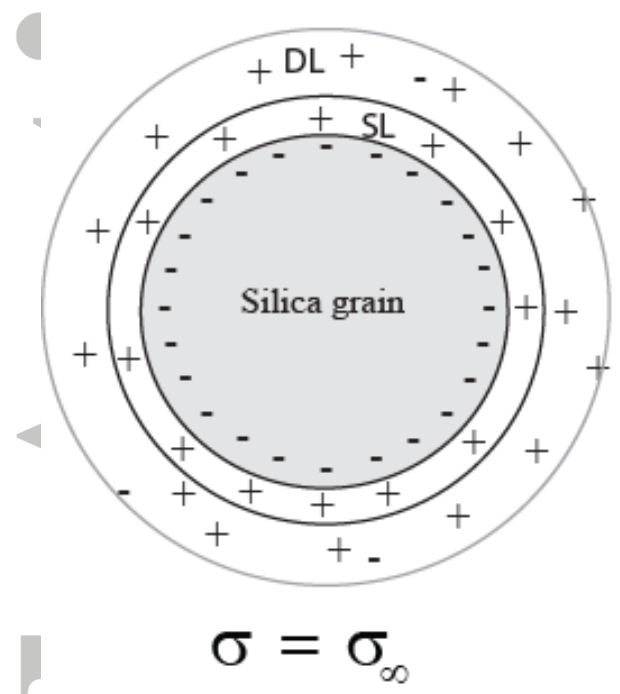

b. $\quad t \rightarrow+\infty$

\section{$E_{0}$}

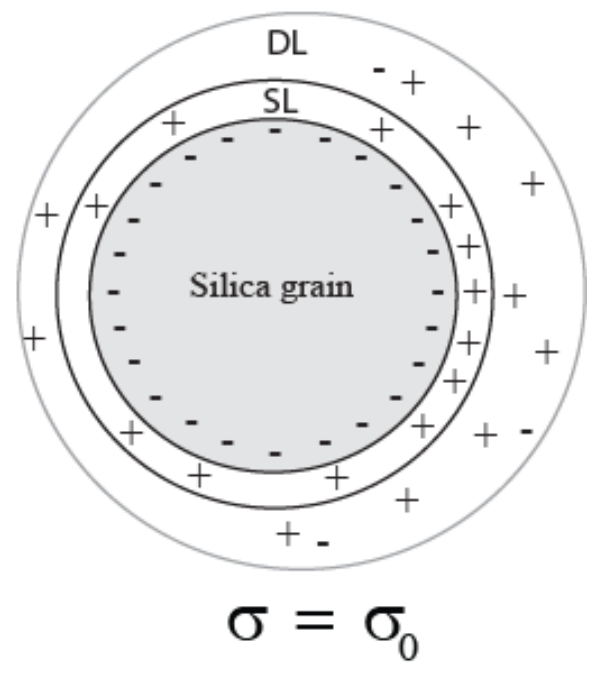

Figure 2. Polarization of a grain coated by an electrical double layer composed by a diffuse layer (DL) and a Stern layer (SL) of weakly sorbed counterions that are mobile along the grain surface but that cannot leave the Stern layer. a. Just after the application of the primary electrical field $\mathbf{E}_{0}$, all the charge carriers are mobile. The instantaneous conductivity is $\sigma_{\infty} . \mathbf{b}$. If the primary electrical field is applied for a long time, the conductivity is $\sigma_{0}=\sigma_{\infty}(1-M)$ where $M$ stands for the chargeability of the material (dimensionless). Some of the charge carriers (those of the Stern layer) are now blocked at the edge of the grain in the direction of the electrical field. As the result, the conductivity of the material is reduced. The time constant $\tau$ would be the relaxation time required for the charge carriers to come back to their equilibrium situation, i.e., to go from the situation described in the right side of the sketch to the situation described in the left side. During the polarization, the grain acquires a dipole moment similar to the phenomenon observed in dielectric polarization. 


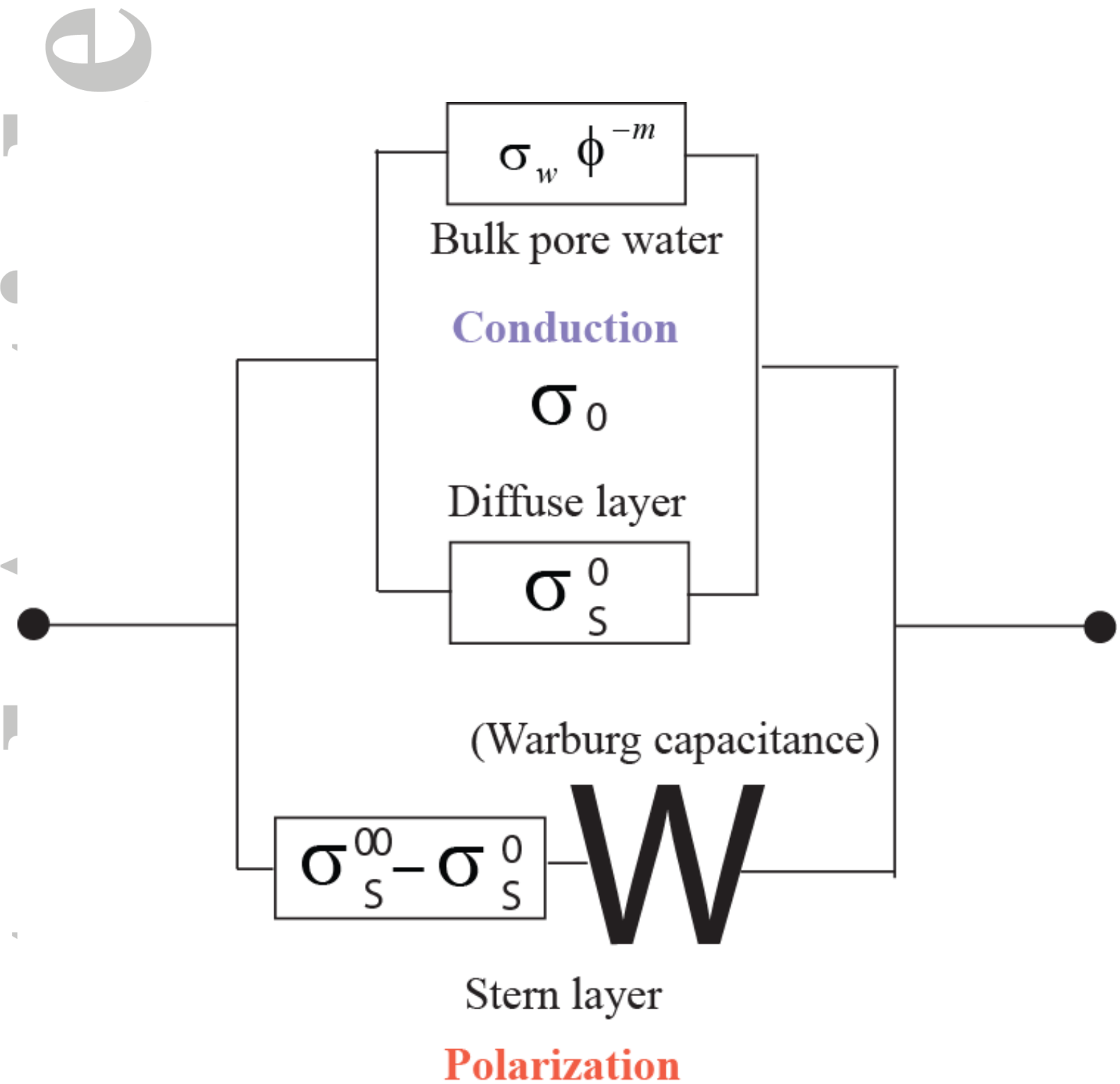

Figure 3. Equivalent circuit of a soil. The conduction corresponds in first approximation to two resistances in parallel, one corresponding to the conduction in the bulk pore water and one associated with conduction on the electrical double layer. This is true only as long as the conduction is essentially dominated by the bulk pore water and the electrical field controlled by the distribution of the bulk conductances of the pore network with surface conductivity as a first-order perturbation with respect to the bulk conductivity. The Stern layer provides another additional conductivity and is responsible for the polarization of the material. The Warburg capacitance is used to model the Stern layer as a leaking capacitance. 


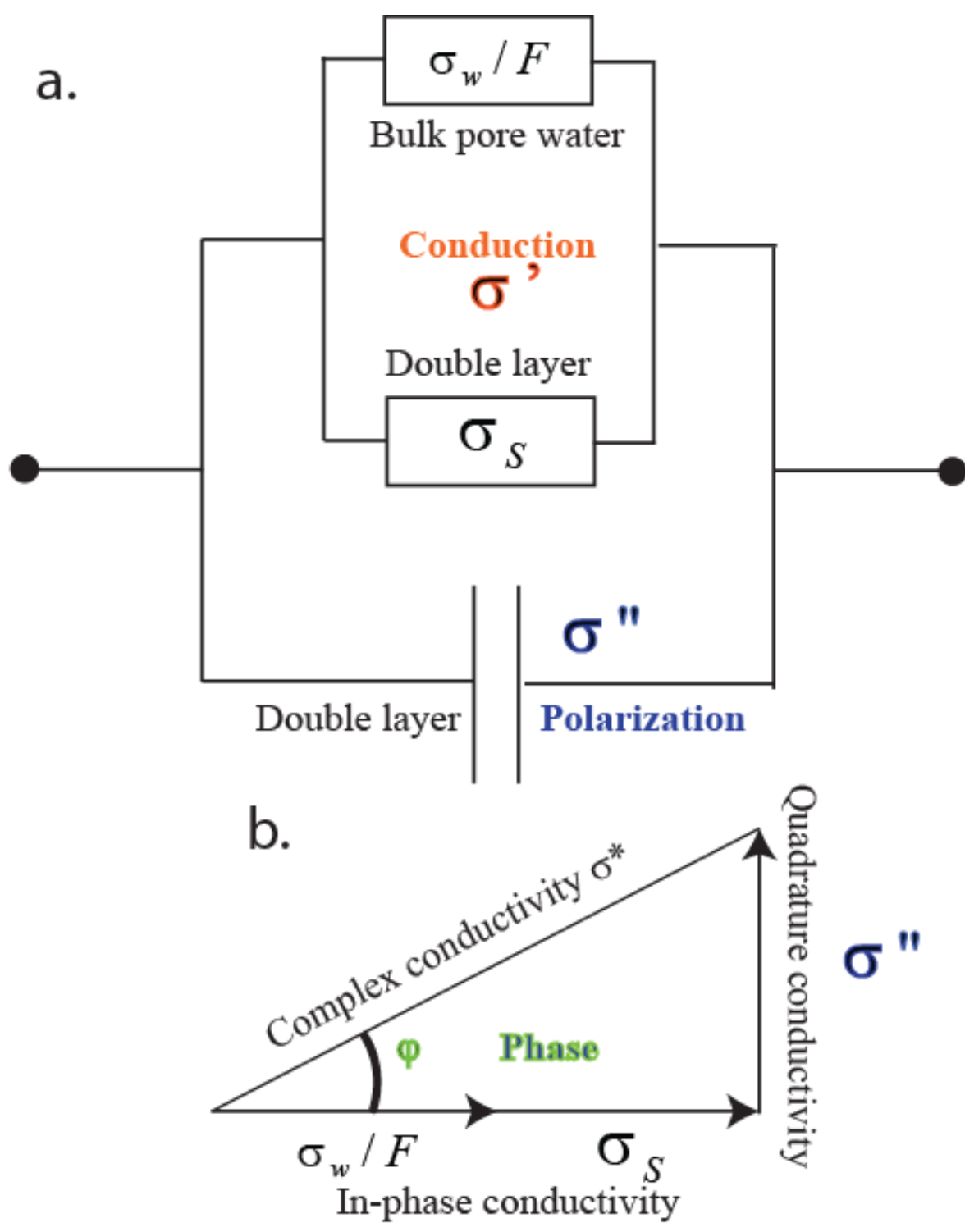

Figure 4. First-order approximation of the equivalent circuit of a soil at high frequencies. a. Equivalent circuit. Conduction associated with the electromigration of the charge carriers comprises two contributions, one associated with the bulk pore water and the other with conduction in the electrical double layer (including the Stern and diffuse layers). The capacitance corresponds to the polarization of the Stern layer coating the surface of the grains (Figure 1). b. Complex conductivity representation. The complex conductivity $\sigma^{*}$ is characterized by an in-phase component and a quadrature component. The tangent of the phase angle $\varphi$ represents the ratio between polarization (described by the quadrature conductivity $\sigma^{\prime \prime}$ or the normalized chargeability $M_{n}$ ) and conduction described by the inphase conductivity $\sigma^{\prime}$. This in-phase conductivity is itself the sum of two contributions, a bulk conductivity (given by the conductivity of the pore water $\sigma_{w}$ divided by the formation factor $F$ ) and a surface conductivity $\sigma_{S}$. 

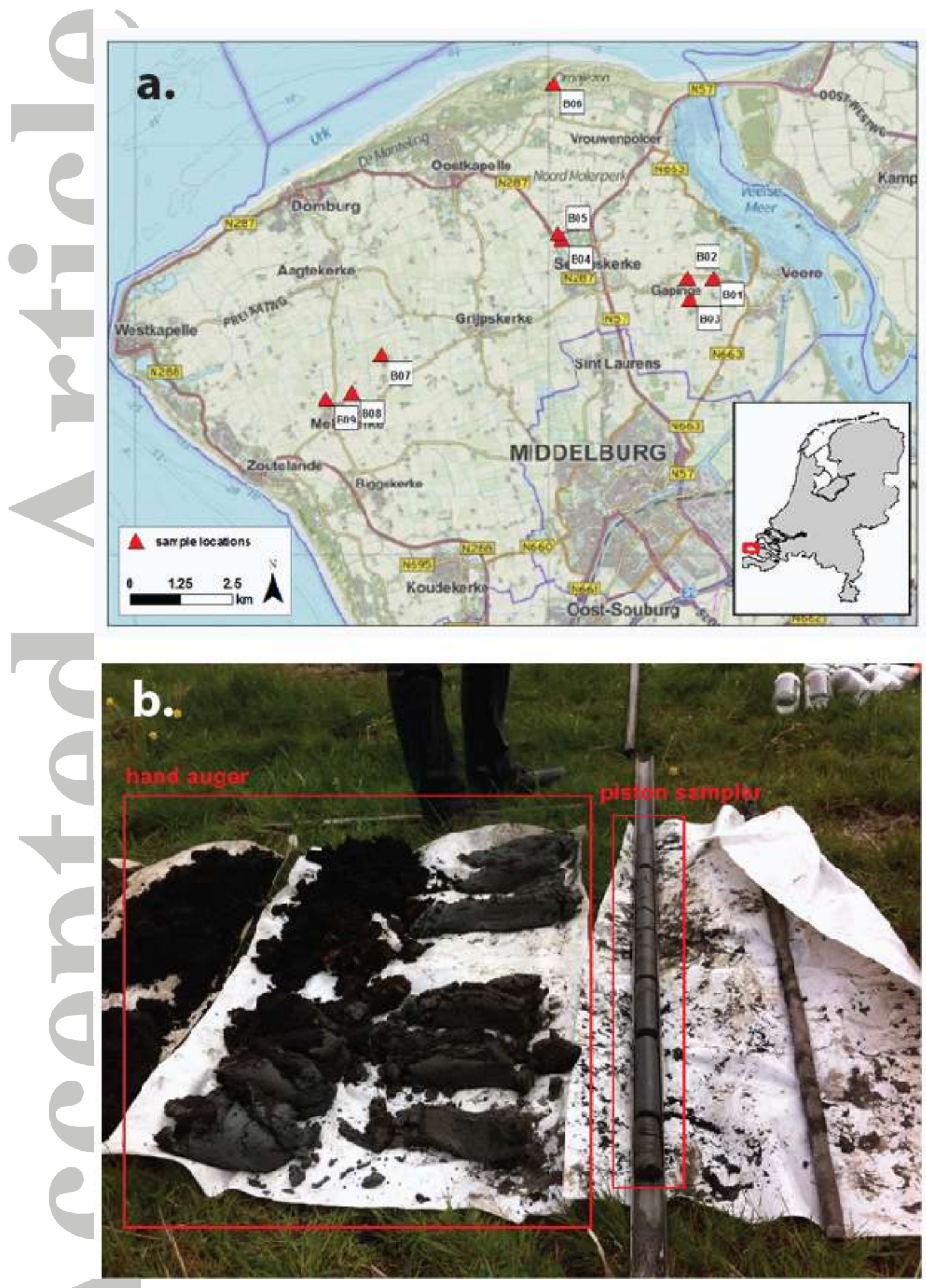

Figure 5. Origin of the core samples. a. Overview of the sample locations on the Walcheren peninsula in the Netherlands. b. Collected sediment at location B08, retrieved using a hand auger (on the left, for sediment above the water table) and piston sampler (on the right, for below the water table). 
a. Sample holder

A, B Current electrodes, M, N Potential electrodes

Amplifier unit b. ZEL-SIP04-V02
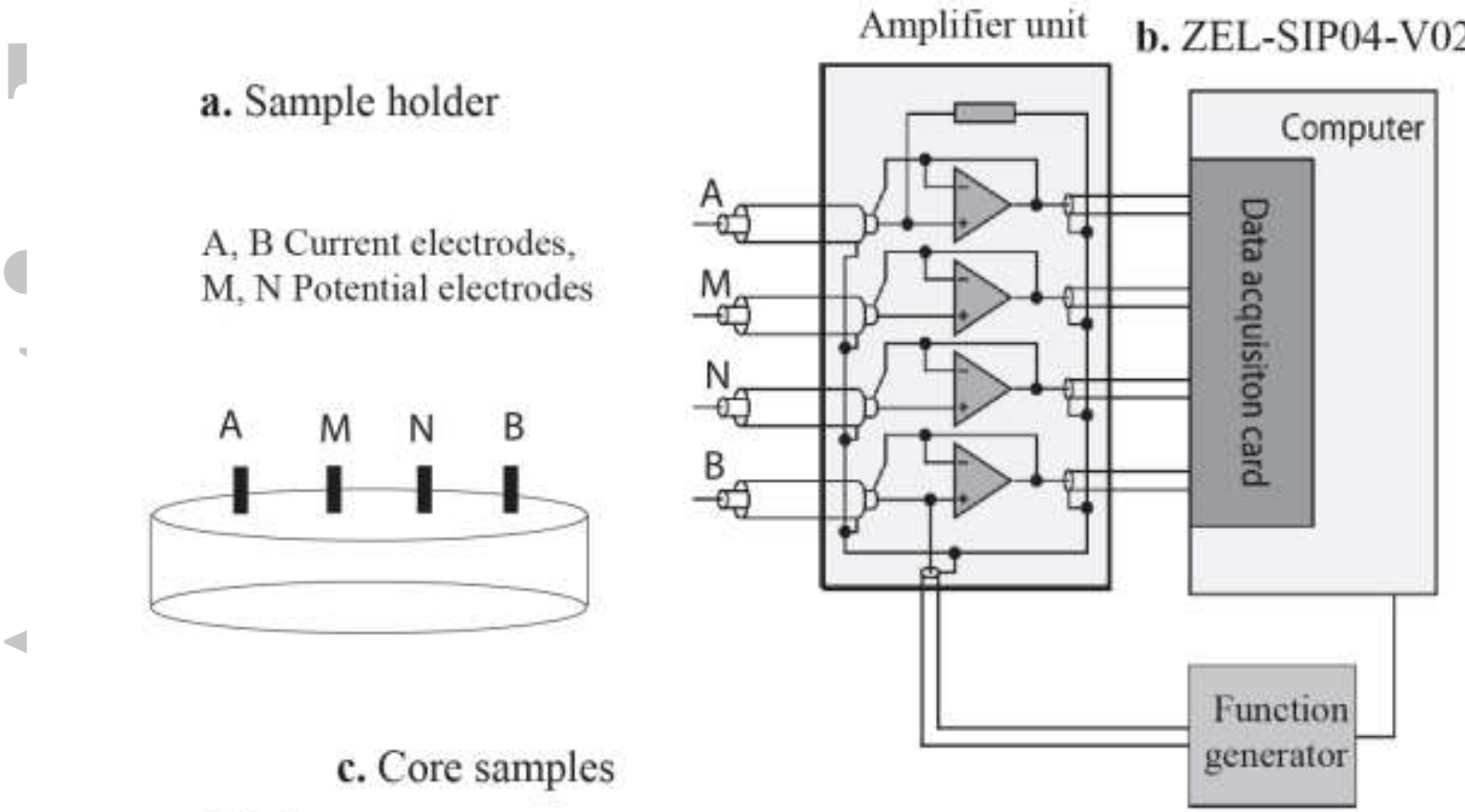

Black peat

Gray sandy clay

Gray black clay
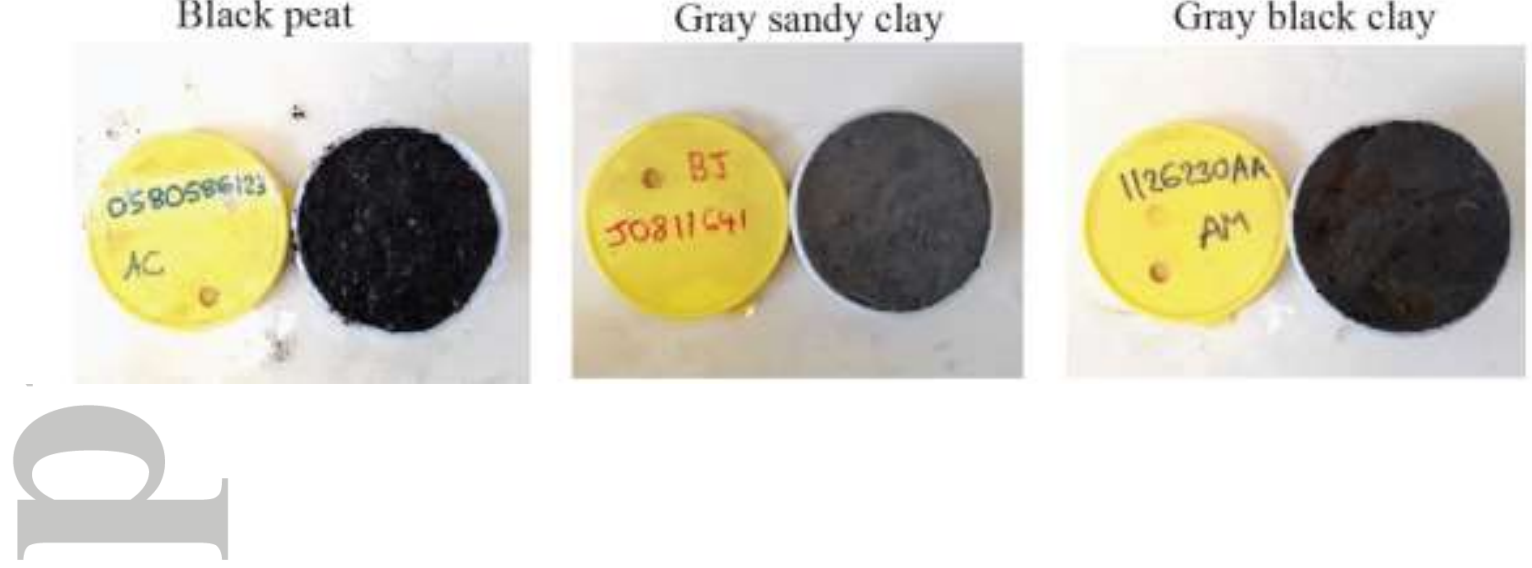

Figure 6. Impedance meter, position of the electrodes, and core samples. a. Position of the A$\mathrm{B}$ current electrodes and $\mathrm{M}-\mathrm{N}$ voltage electrodes on the surface of the core samples. The distance between the electrodes is $2 \mathrm{~cm}$, the height of the sample holder is $2.5 \mathrm{~cm}$, and its diameter is $7.0 \mathrm{~cm}$. The four $\mathrm{Ag}-\mathrm{AgCl}_{2}$ electrodes (diameter $4 \mathrm{~mm} \times 1 \mathrm{~mm}$ ) are glued on a cap used to prevent evaporation during the measurements. b. ZEL-SIP04-V02 impedance meter (see Zimmermann et al. [2008]) used for the laboratory experiments. The current electrodes $\mathrm{A}$ and $\mathrm{B}$ are non-polarizing $\mathrm{Ag}-\mathrm{AgCl}$ electrodes. Two (point) potential electrodes $\mathrm{M}$ and $\mathrm{N}$ are non-polarizing $\mathrm{Ag}-\mathrm{AgCl}$ electrodes. The geometrical factor is computed from numerical modeling using Comsol Multiphysics as well as calibrated using 5 brines of independently determined electrical conductivity. c. Three examples of core samples. 

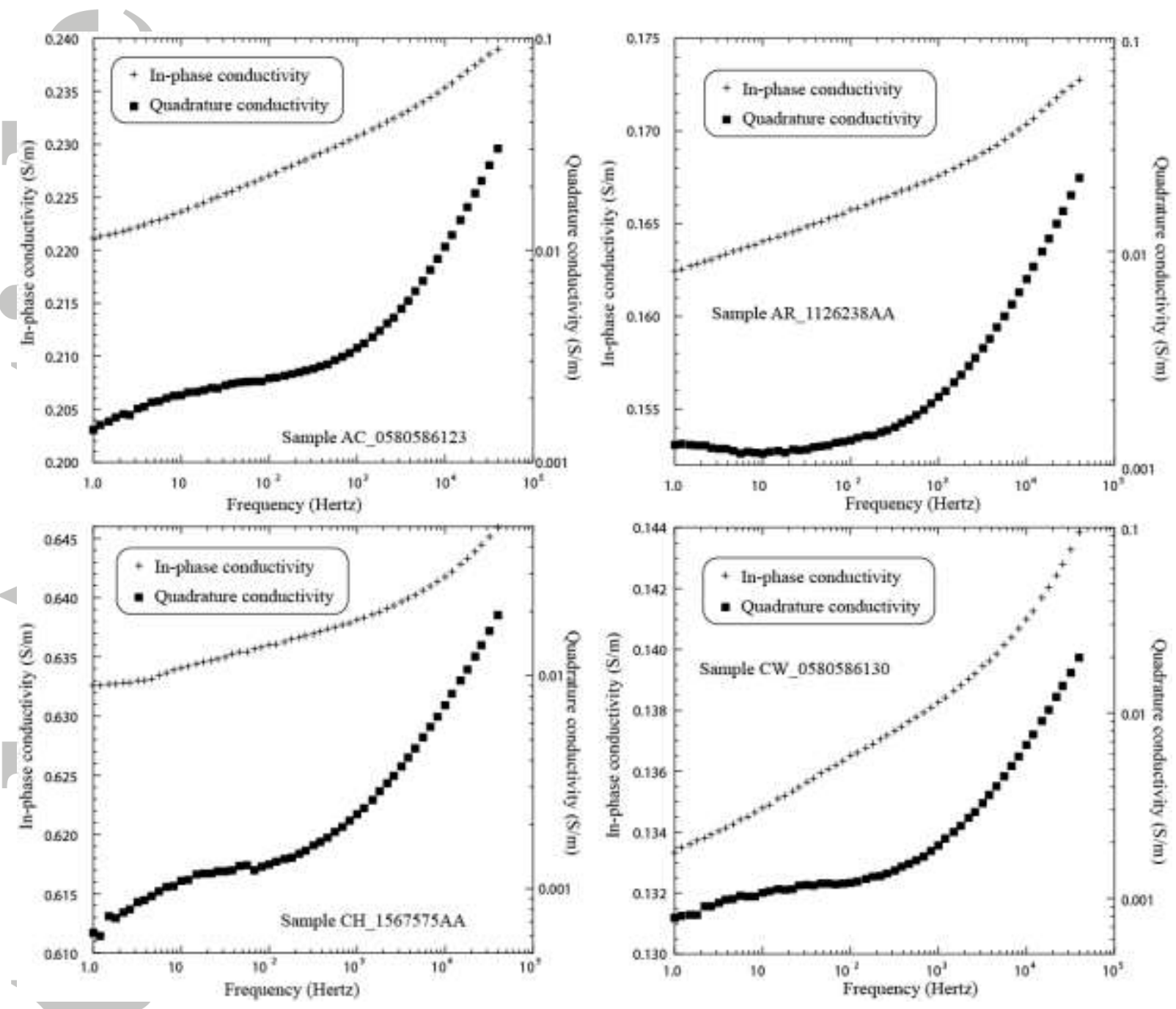

Figure 7. Complex conductivity spectrum (real/in-phase and absolute value of the imaginary/quadrature components). Sample AC_0580586123 (black peat), Sample AR_1126238AA (sandy clay), Sample CH_1567575AA (sandy clay), Sample CW_ 0580586130 (clay). The strong increase of the quadrature conductivity above $1 \mathrm{kHz}$ corresponds to dielectric phenomena including the Maxwell Wagner polarization. Spectra are reported here at the lowest salinity. 

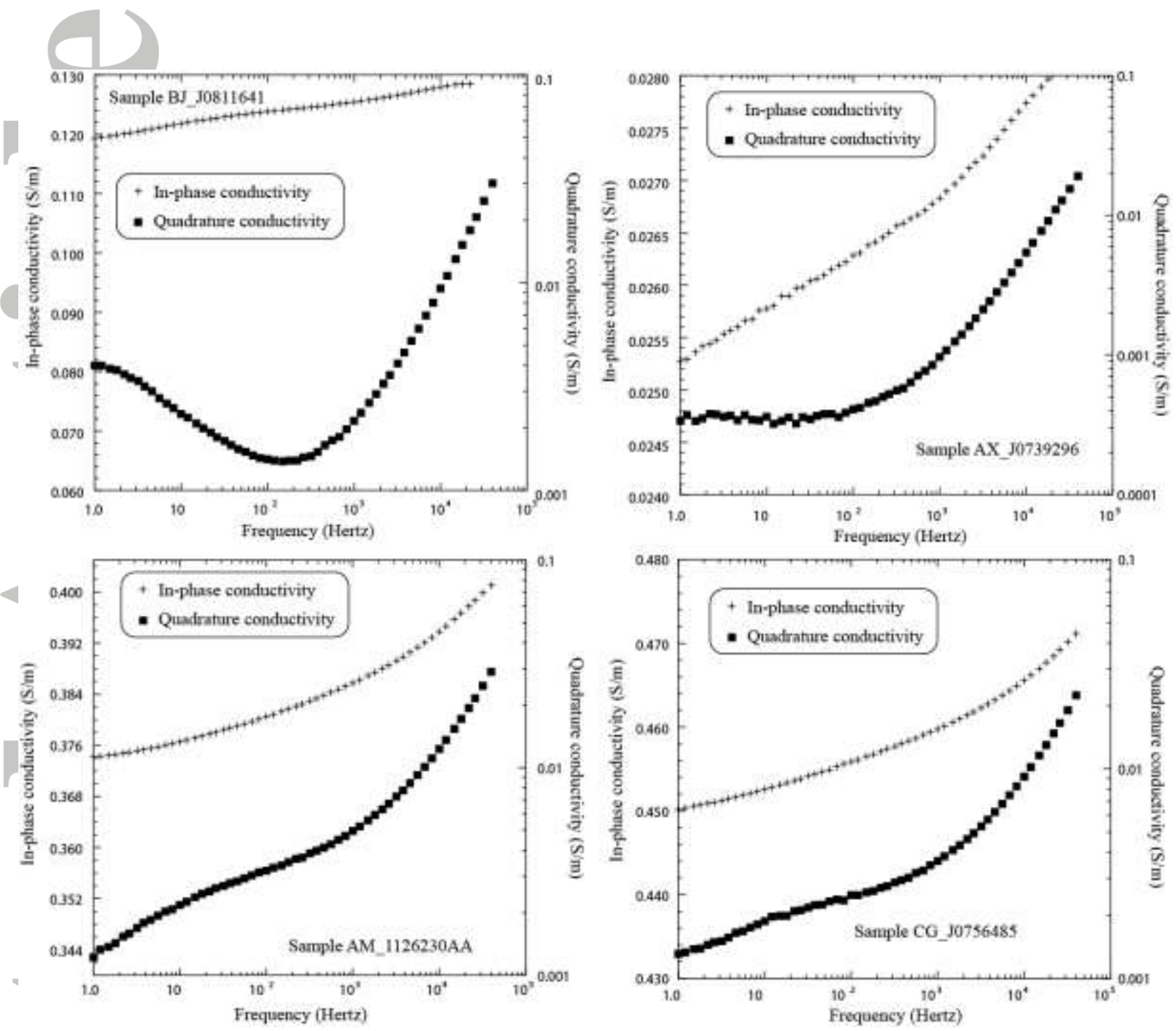

Figure 8. Complex conductivity spectrum (real/in-phase and absolute value of the imaginary/quadrature components). Sample BJ_J0811641 (Gray sandy clayey soil), sample AM-1126230AA (Gray/black clayey soil), sample AX_J0739296 (fine sand), and sample CG_J0756485 (clay). The strong increase of the quadrature conductivity above $1 \mathrm{kHz}$ corresponds to dielectric phenomena including the Maxwell Wagner polarization. Spectra are reported here at the lowest salinity. 


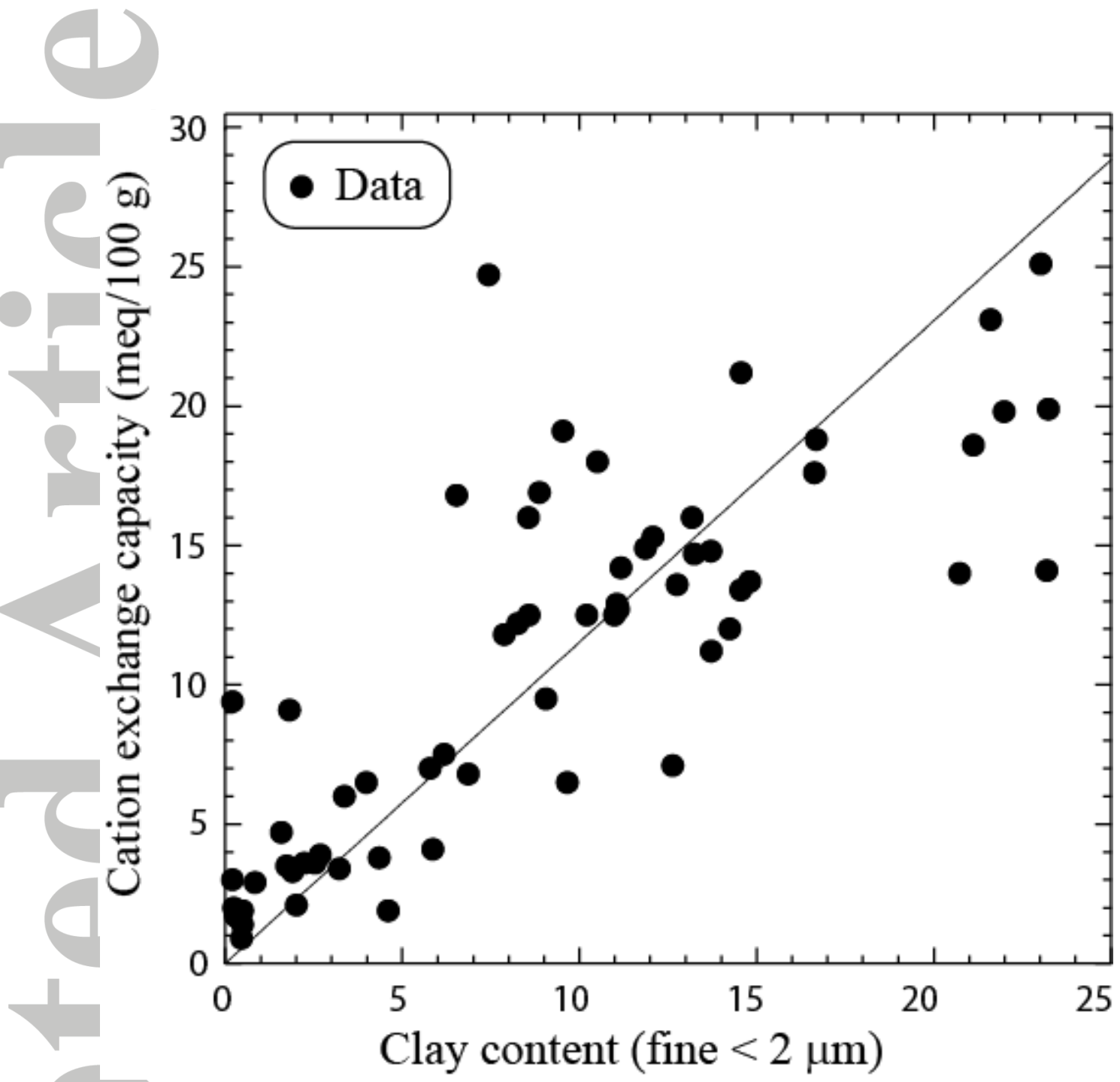

Figure 9. Relationship between the cation exchange capacity (CEC) and the clay content taken as the weight fraction of fine particles smaller than $2 \mu \mathrm{m}$. The data are scattered because of the effect of humus and variations between the core sample in the clay mineralogy. 


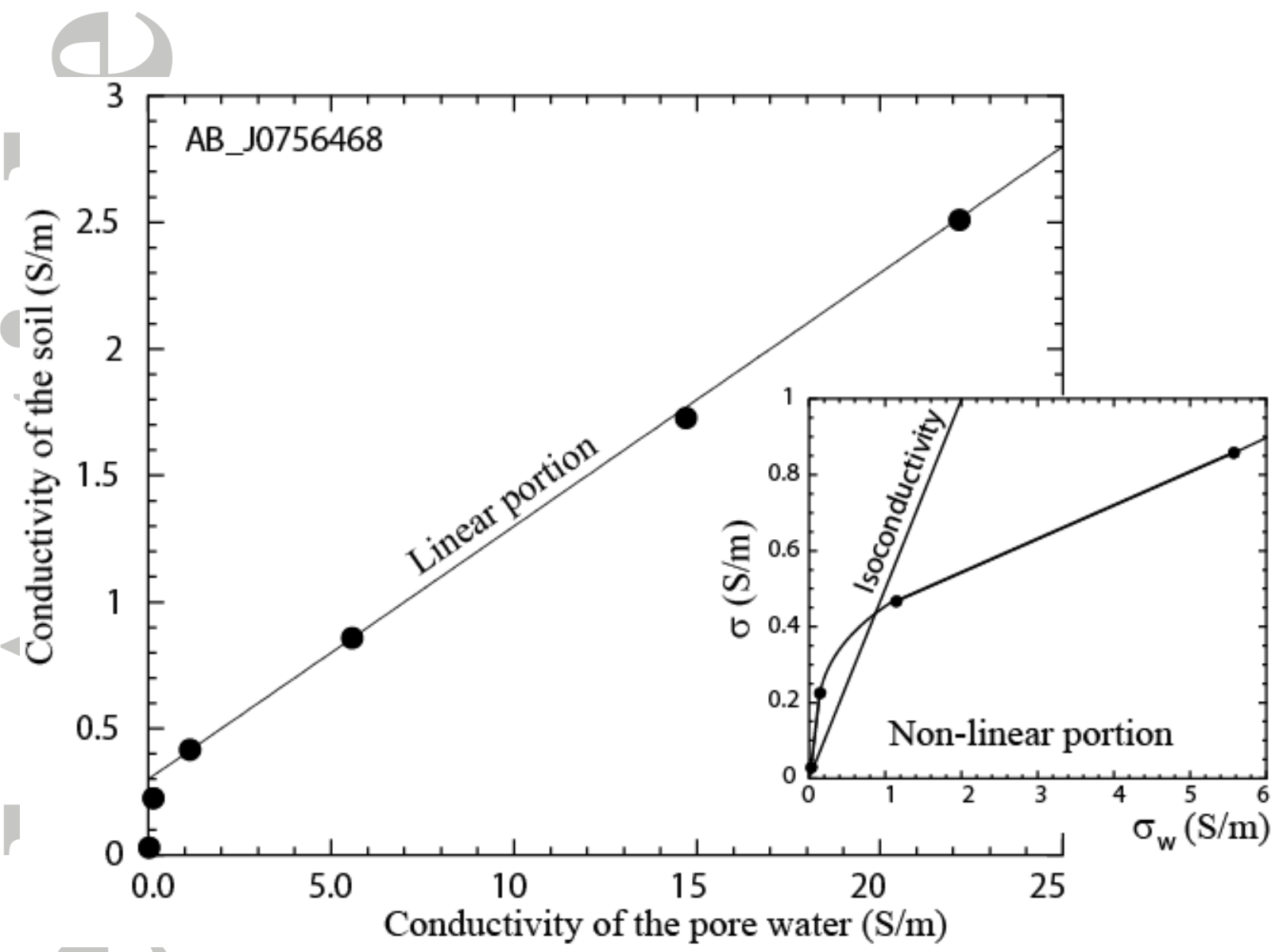

Figure 10. Conductivity versus pore water conductivity showing the linear (obeying to equation 5) and non-linear portions of the conductivity plot. The non-linear portion at low salinities is due to a change in the tortuosity of the conduction paths. The quantities $\sigma$ and $\sigma_{w}$ define the conductivity of the soil and the conductivity of the pore water. 

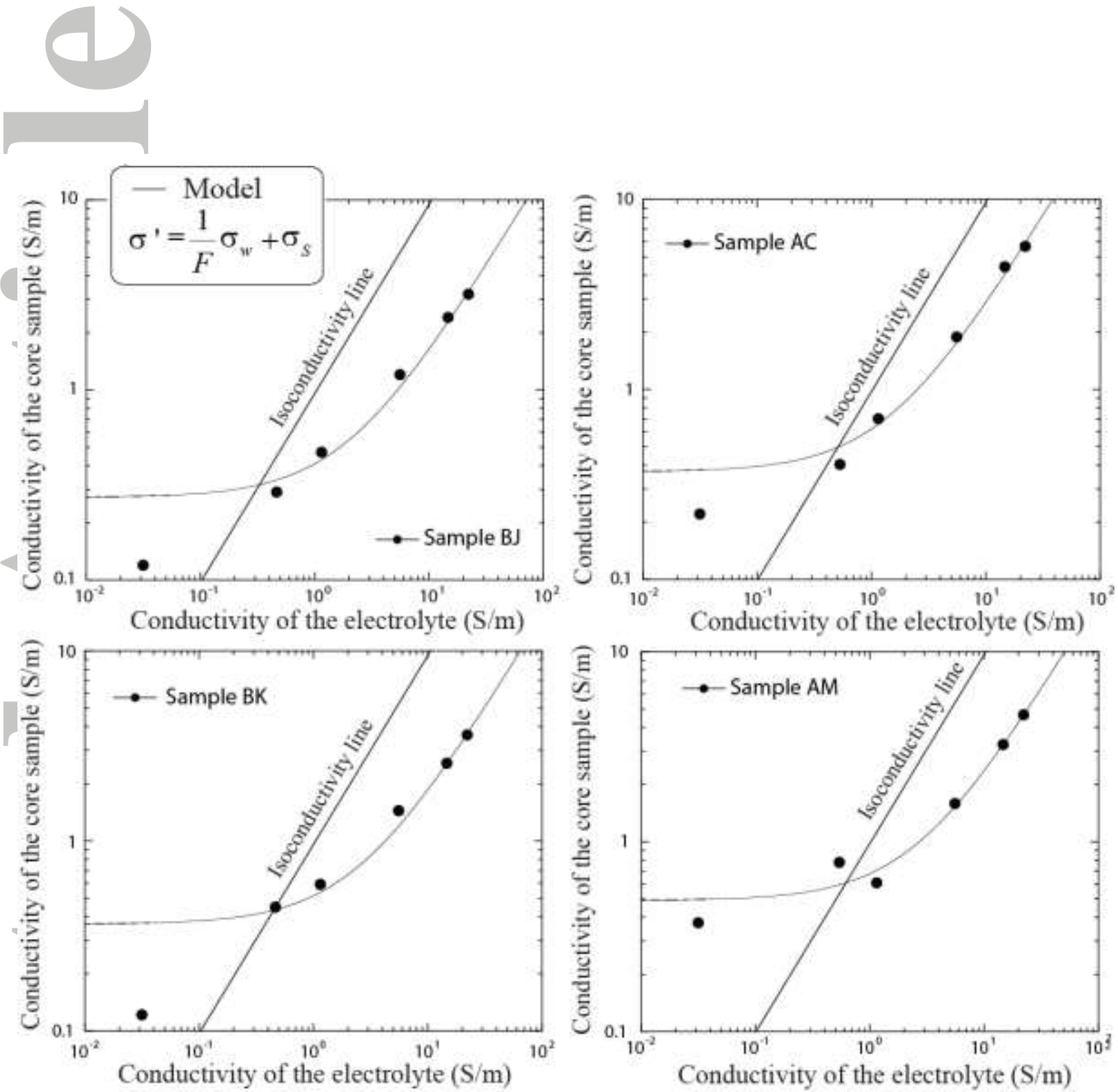

Figure 11. Conductivity of the material versus the pore water conductivity for 4 samples (AC: Black peat, AM: Gray/black clay, BG: Gray clay, BK: Gray sandy clay). We see clearly that the data exhibit an isoconductivity point (at the intersection of the two curves, one being the isoconductivity line and the other the linear conductivity model, see equation 5). 

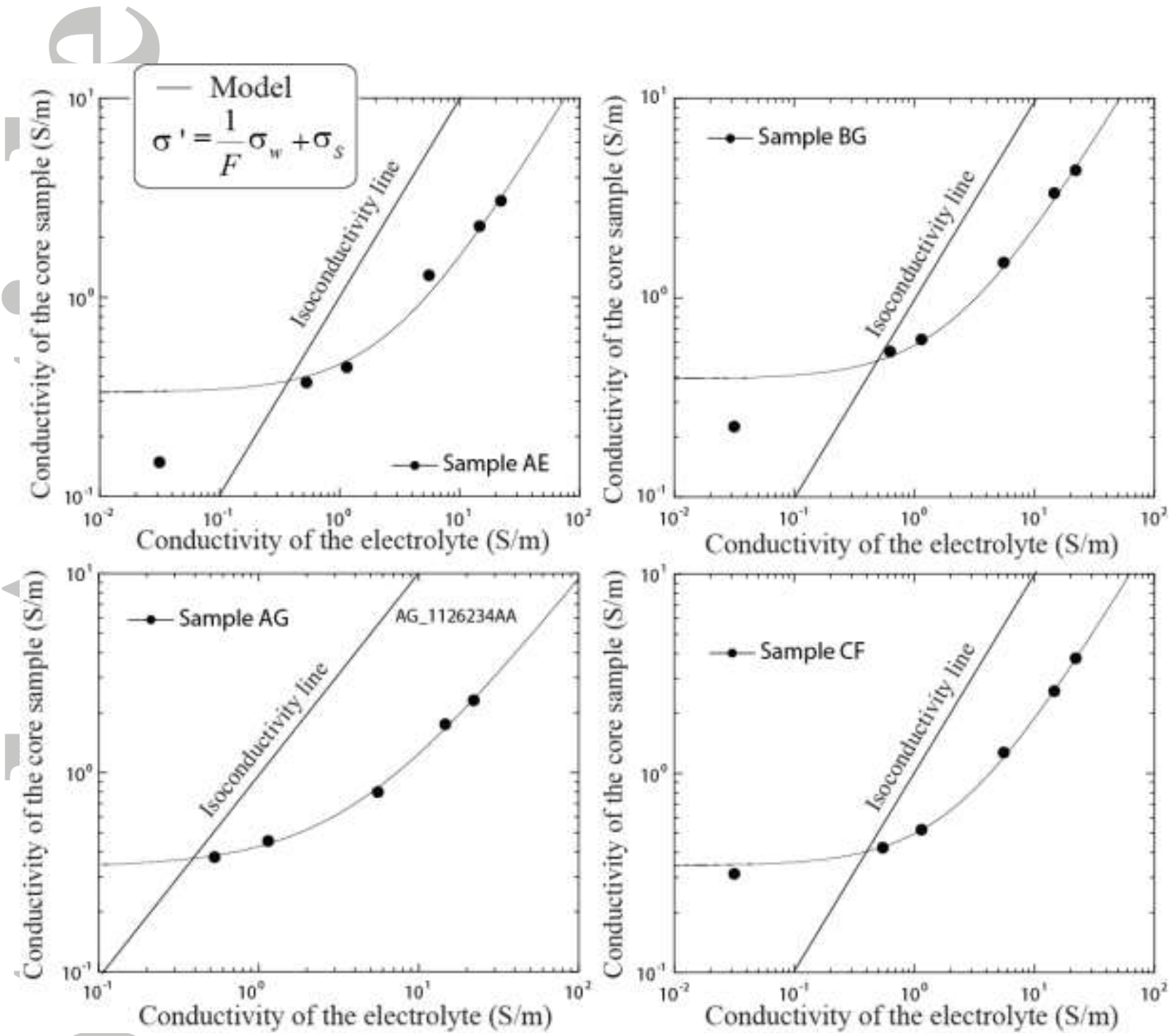

Figure 12. Conductivity of the material versus the pore water conductivity for 4 samples (AE: Dark sandy clay, AG: gray sand, CF: gray clay, BG: gray clay). We see clearly that the data exhibit an isoconductivity point (at the intersection of the two curves, one being the isoconductivity line and the other the linear conductivity model, see equations 5). 


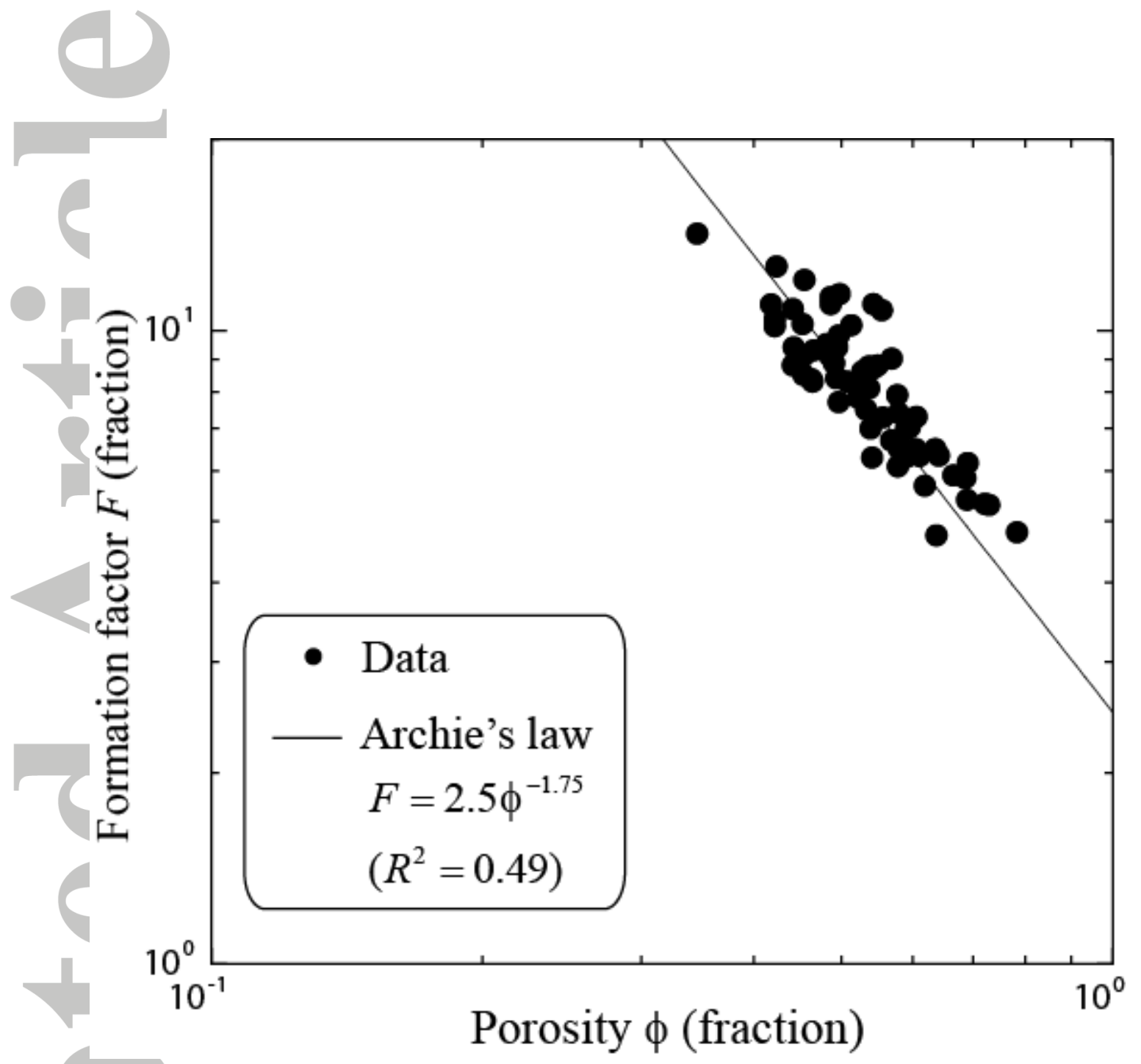

Figure 13. Relationship between the formation factor and the porosity and fit with the empirical Archie's law (peat samples excluded). 


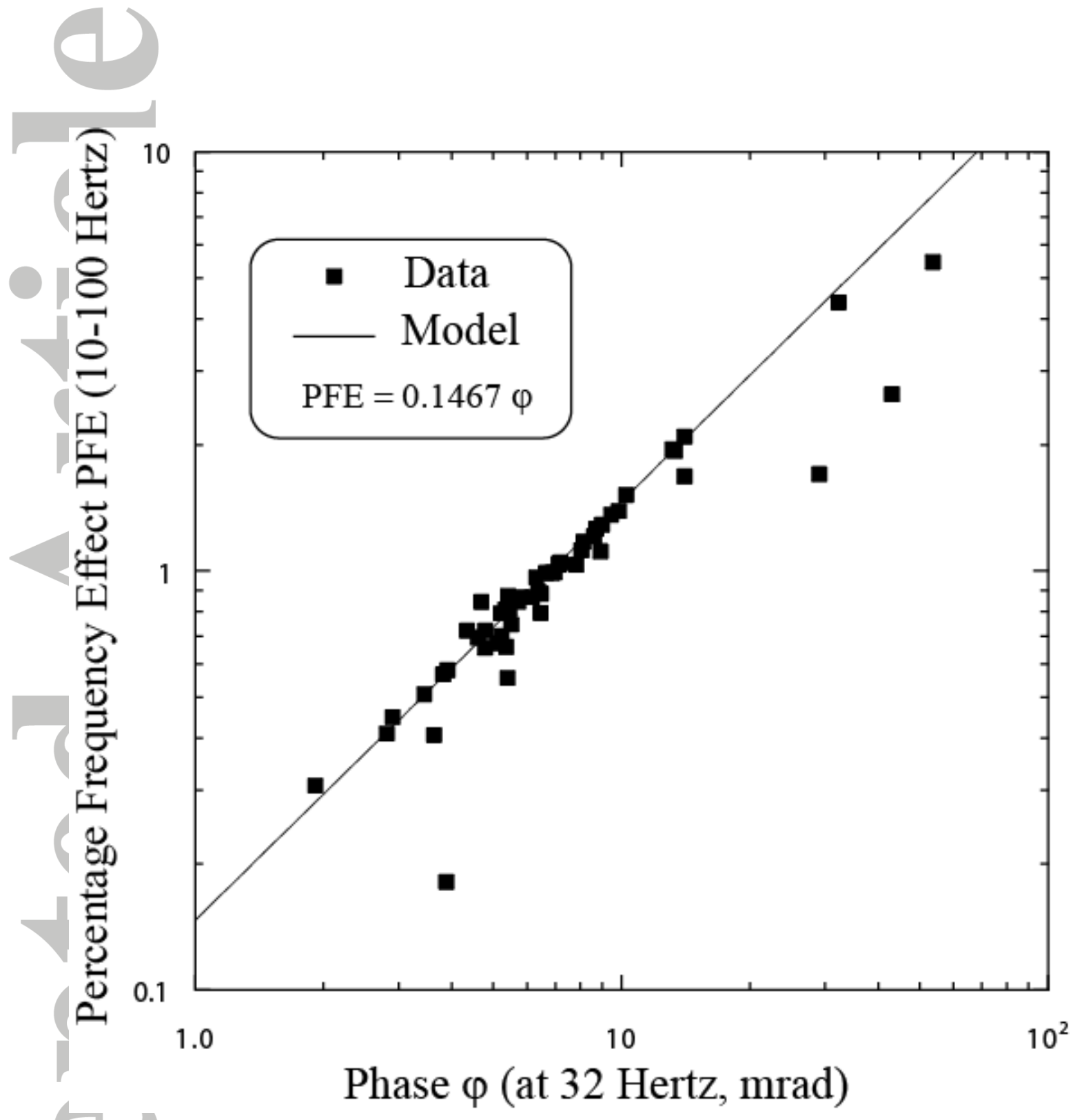

Figure 14. Relationship between the percentage frequency effect PFE and the phase (at the geometric frequency) for the low salinity dataset. The theoretical prediction $\mathrm{PFE}=100 \mathrm{FE} \approx 0.1467 \varphi$ is also shown for comparison. The three points outside the trends are considered to be problematic. 


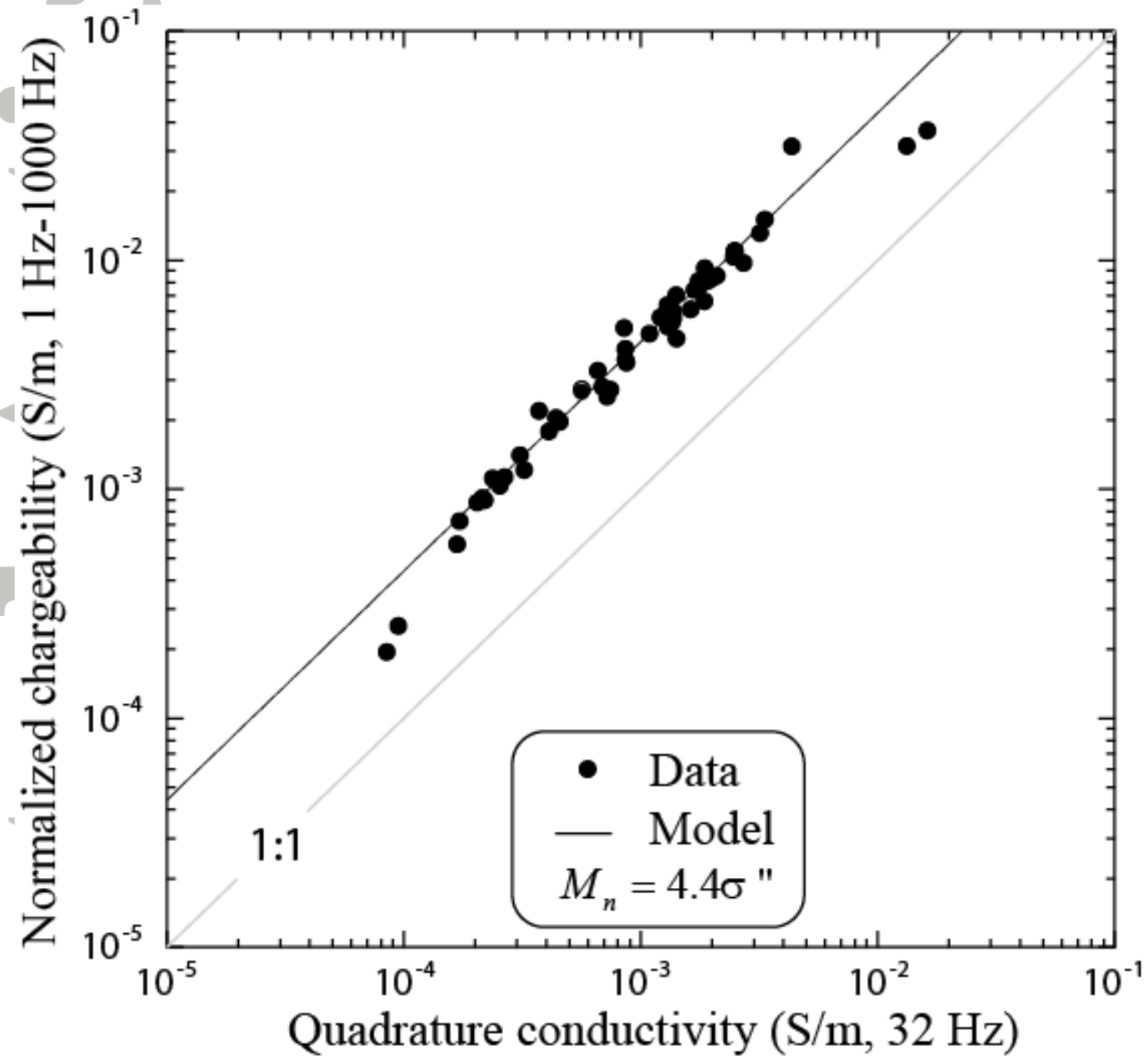

Figure 15. Relationship between the normalized chargeability (between 1 Hertz and 1 kHertz) and the quadrature conductivity (at the geometric frequency of 32 Hertz) for the low salinity dataset. The theoretical prediction is $M_{n} \approx-4.4 \sigma^{\prime \prime}$ is also shown for comparison. The points outside the trends are considered to be problematic.

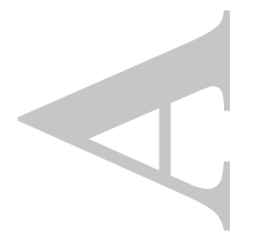




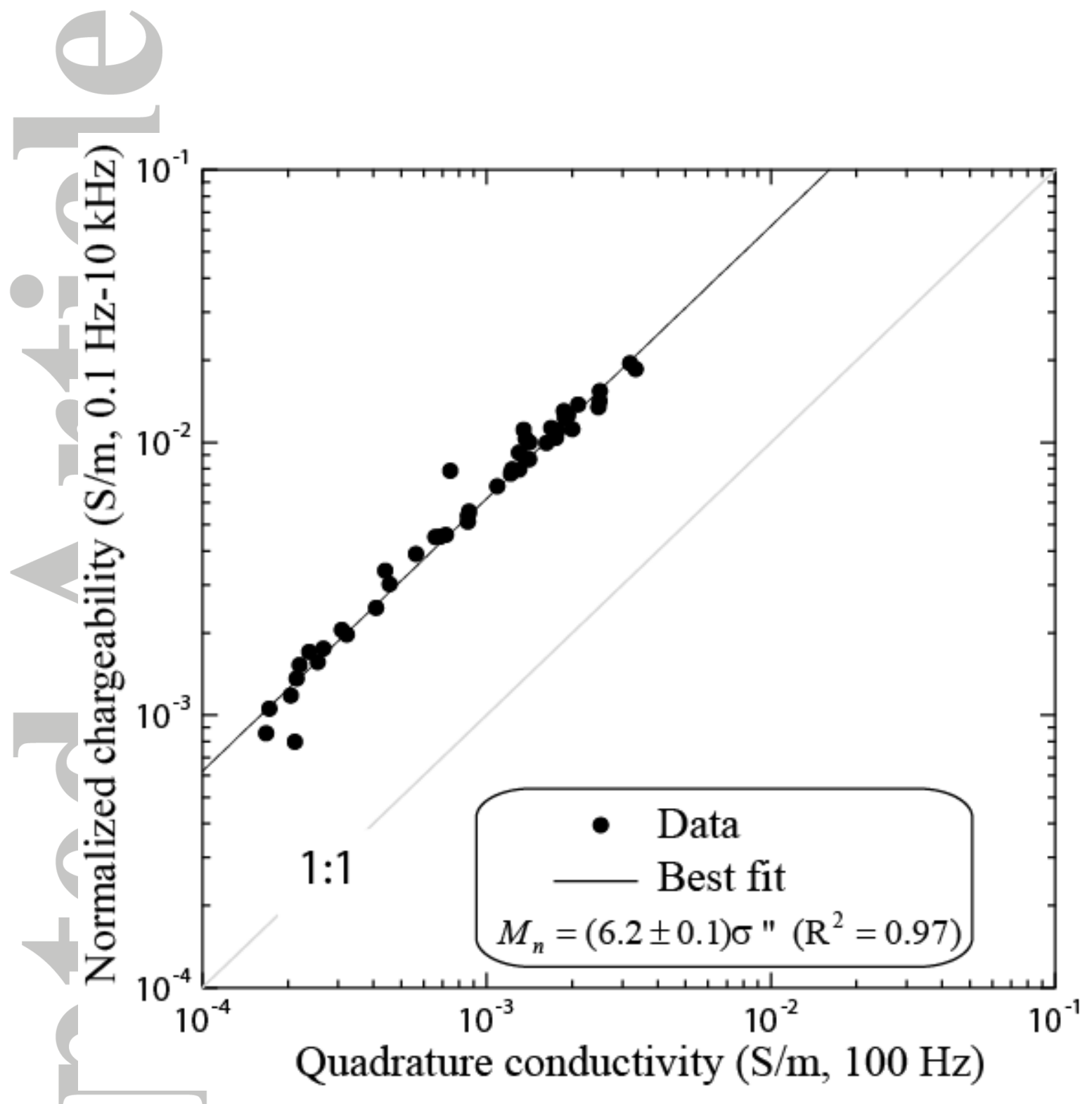

Figure 16. Relationship between the normalized chargeability and the quadrature conductivity for the low salinity dataset and the frequency range $0.1 \mathrm{Hertz}-10 \mathrm{kHz}$. The theoretical prediction is $\alpha \approx-(2 / \pi) \ln D$. If we assume that high and low frequencies are separated by 5 decades $\left(D=10^{5}\right)$, we obtain $\alpha \approx 5.9$ consistent with the best fit of the data $(6.2 \pm 0.1)$. 


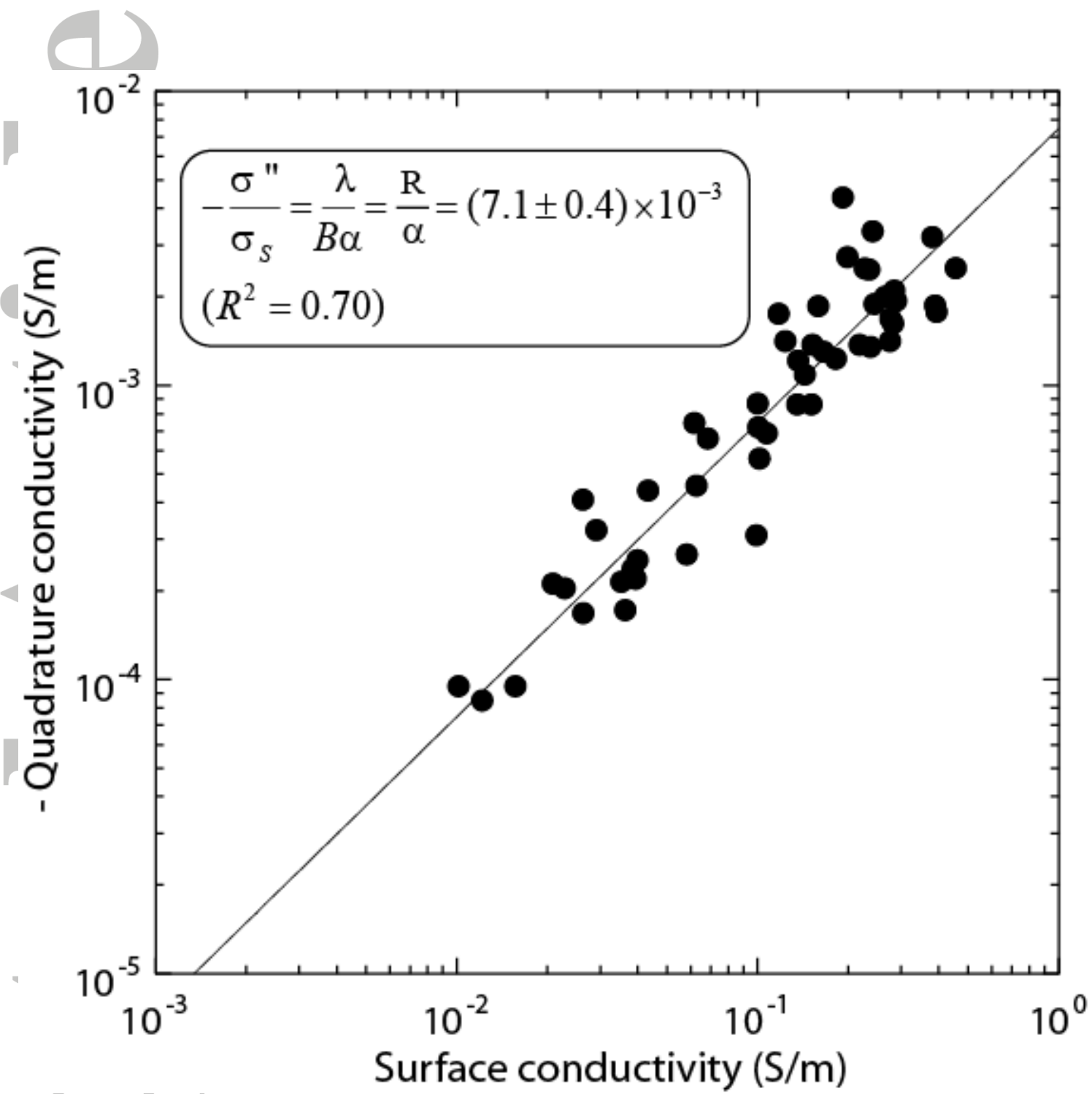

Figure 17. Direct linear relationship between quadrature conductivity and surface conductivity for the soil samples at the low pore water conductivity of $0.03 \mathrm{~S} \mathrm{~m}^{-1}(\mathrm{NaCl}$, $25^{\circ} \mathrm{C}$ ). Here we are below the isoconductivity point and the surface conductivity is considered to be directly equal to the in-phase conductivity. Both the in-phase and quadrature conductivity are taken at 100 Hertz. Taking $\alpha=8$, this yields $\mathrm{R}=0.057$. 


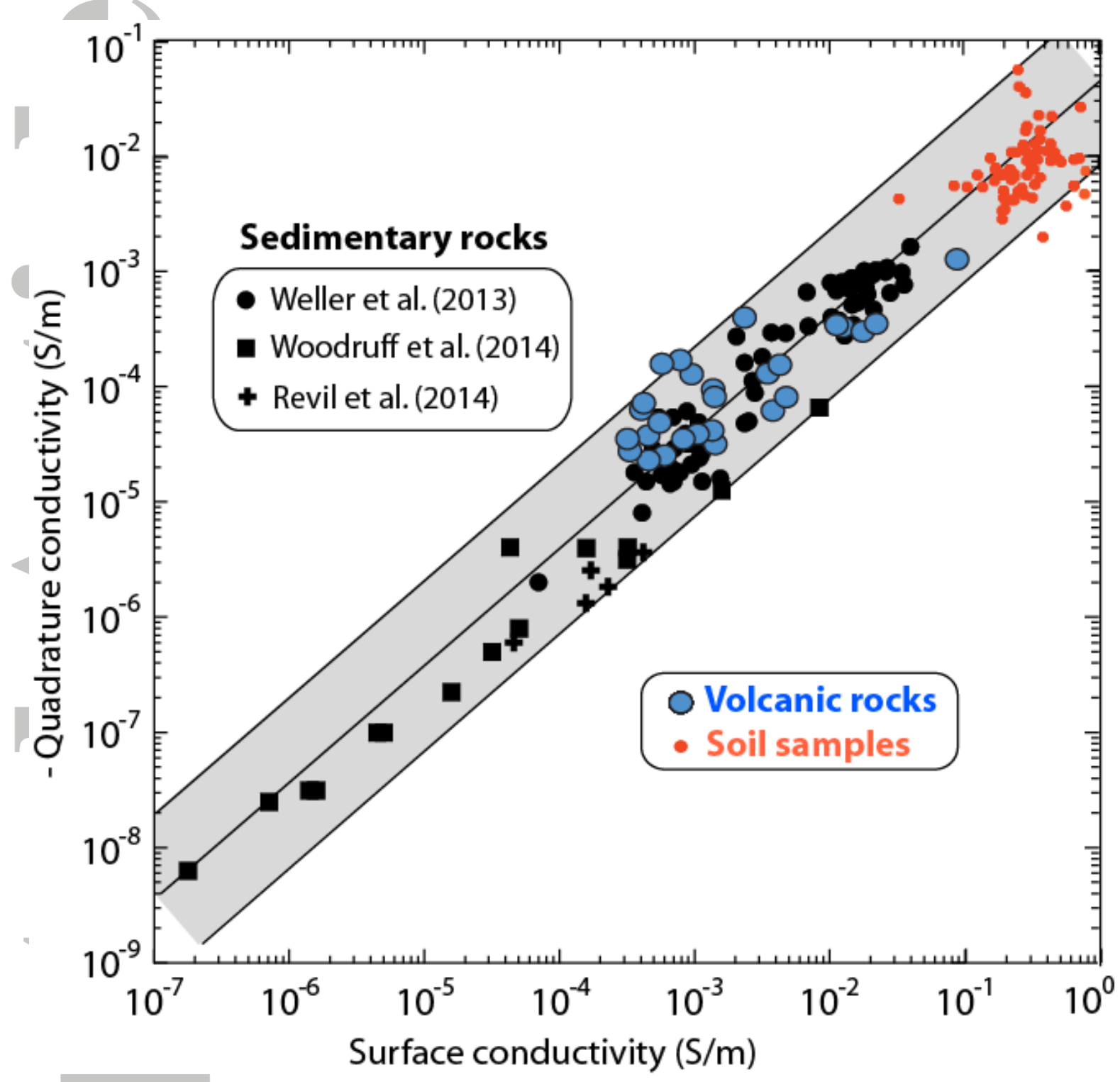

Figure 18. Direct linear relationship between quadrature conductivity and surface conductivity over seven orders in magnitude in the variations of the two parameters. Note that the soil samples (in red) are characterized by higher surface conductivity and quadrature conductivity than the other core samples investigated to date. The other data for sedimentary rocks are from Weller et al. [2013], Woodruff et al. [2014], and Revil et al. [2014b]. The data for the volcanic rocks are from Revil et al. [2017a, b]. 


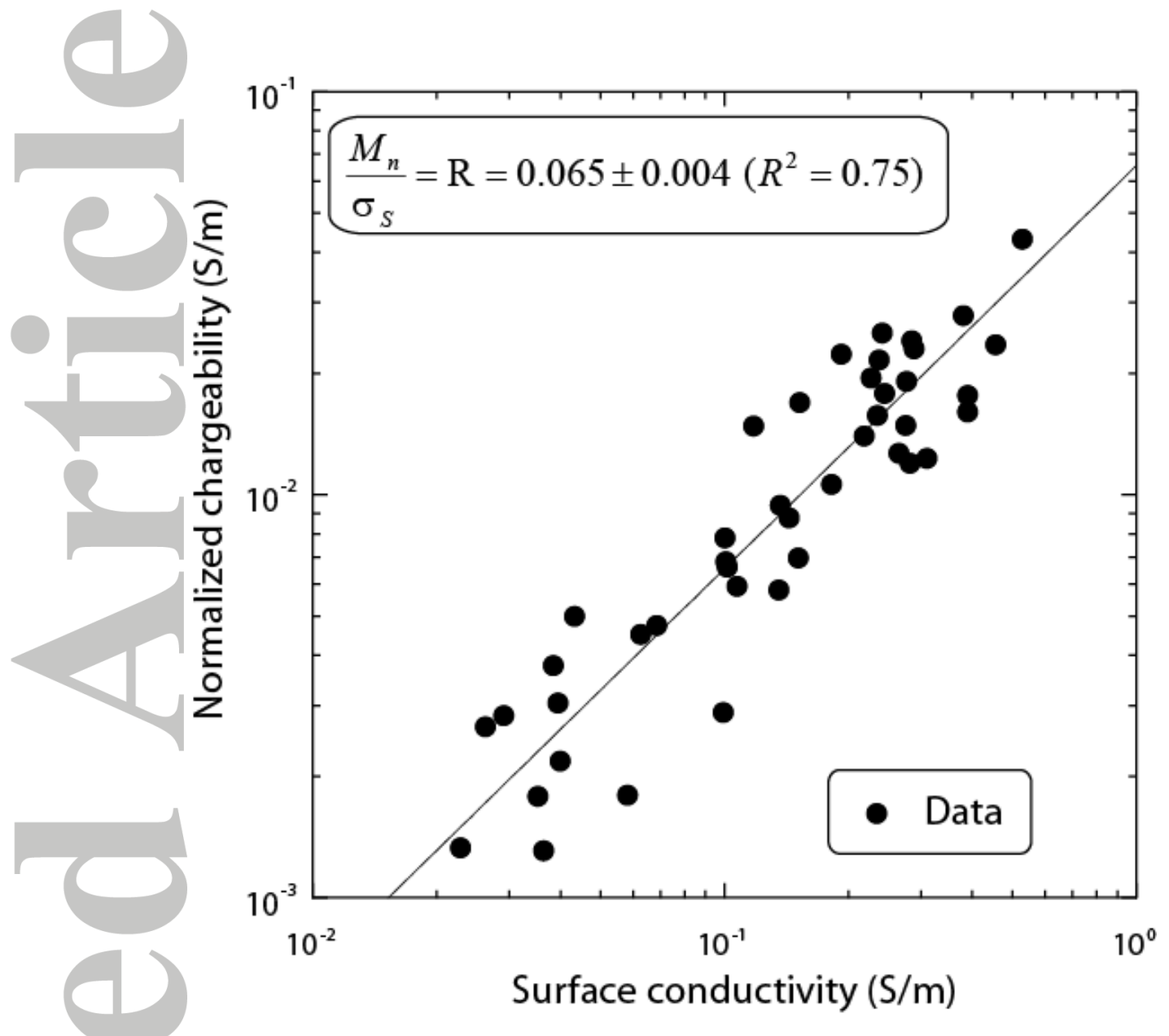

Figure 19. Linear relationship between normalized chargeability (between 0.1 Hertz and 40 $\mathrm{kHz})$ and surface conductivity for the soil samples at $0.03 \mathrm{~S} \mathrm{~m}^{-1}\left(\mathrm{NaCl}, 25^{\circ} \mathrm{C}\right)$. The plain line corresponds to the best fit of the data using a linear model between the normalized chargeability and the surface conductivity. 


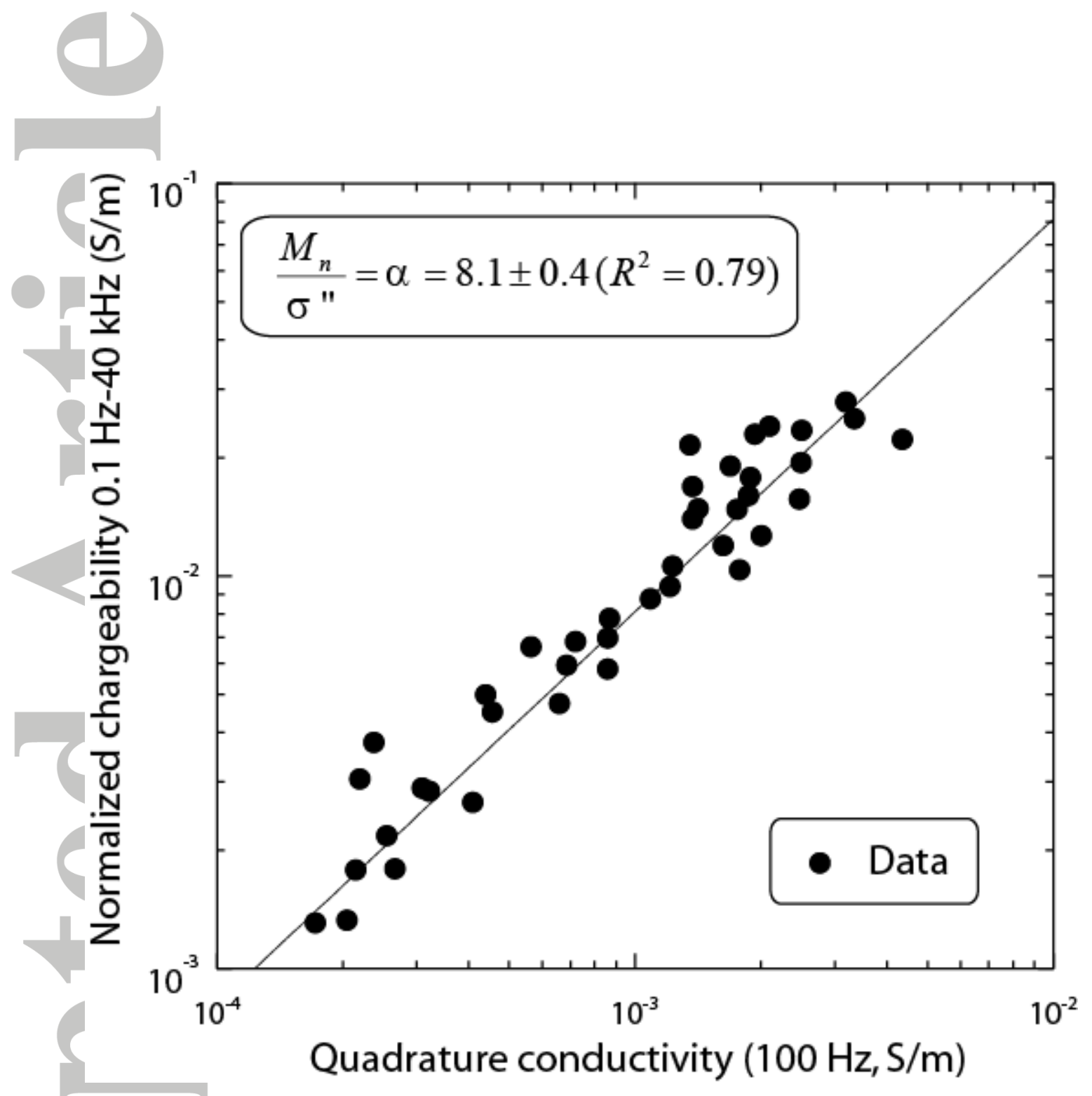

Figure 20. Linear relationship between normalized chargeability (between 0.1 Hertz and 40 $\mathrm{kHz}$ ) and the magnitude of the quadrature conductivity (at $100 \mathrm{Hertz}$ ) for the soil samples at $0.03 \mathrm{~S} \mathrm{~m}^{-1}\left(\mathrm{NaCl}, 25^{\circ} \mathrm{C}\right)$. The plain line corresponds to the best fit of the data using a linear model between the normalized chargeability and the quadrature conductivity. 
a.

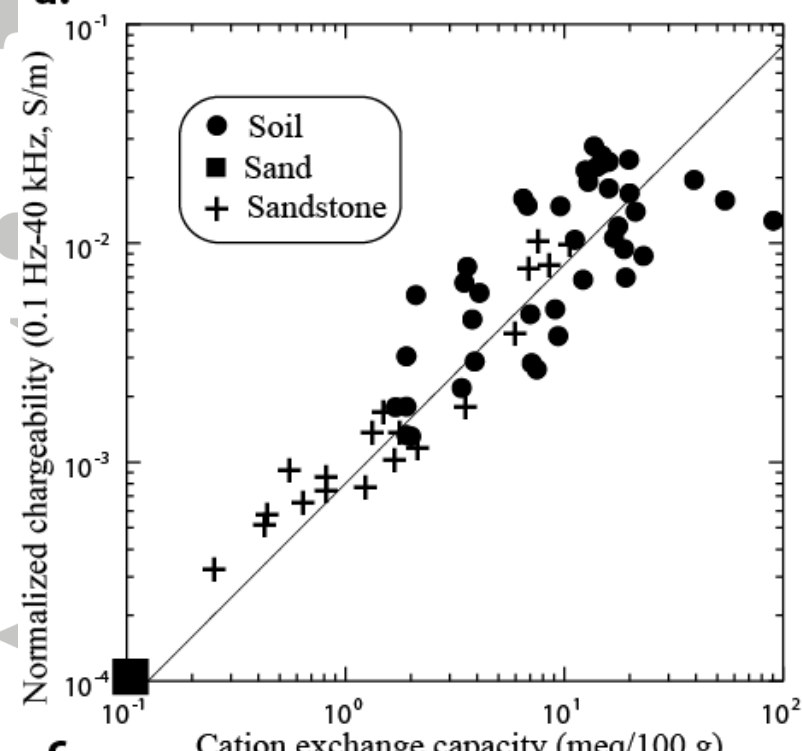

c.

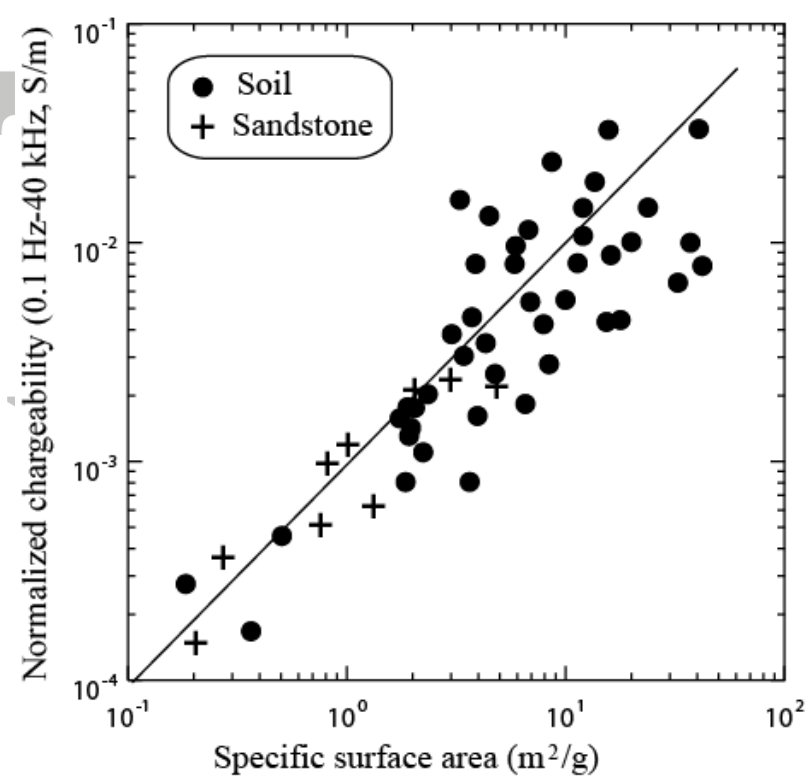

b.
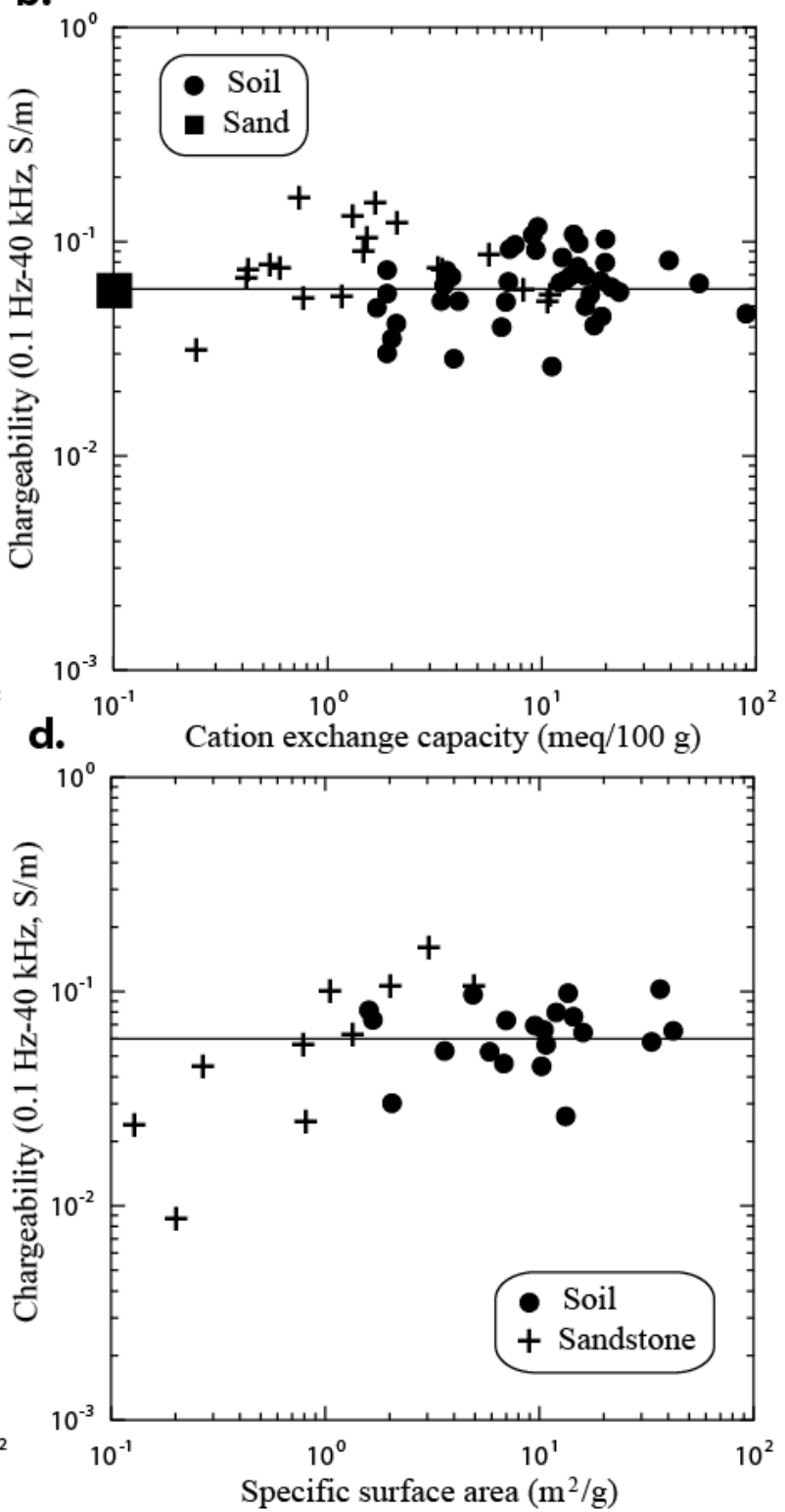

Figure 21. Linear relationship between the normalized chargeability (between 0.1 Hertz and $40 \mathrm{kHz})$ and the chargeability for the soil samples at $0.03 \mathrm{~S} \mathrm{~m}^{-1}\left(\mathrm{NaCl}, 25^{\circ} \mathrm{C}\right)$ versus either the cation exchange capacity and the specific surface area. a. Normalized chargeability versus CEC. b. Chargeability versus CEC. For a) and b) the sandstone data are from Vinegar and Waxman [1984] (all samples at the lowest salinity, the normalized chargeability are obtained using his quadrature conductivity data at $0.1 \mathrm{~S} \mathrm{~m}^{-1}$ using $\alpha=8$ ). c. Normalized chargeability versus specific surface area. d. Chargeability versus specific surface area. For b) and c), the sandstone data are from Börner [1992] where the normalized chargeability are obtained using his quadrature conductivity data at $0.1 \mathrm{~S} \mathrm{~m}^{-1}$ using $\alpha=8$. 

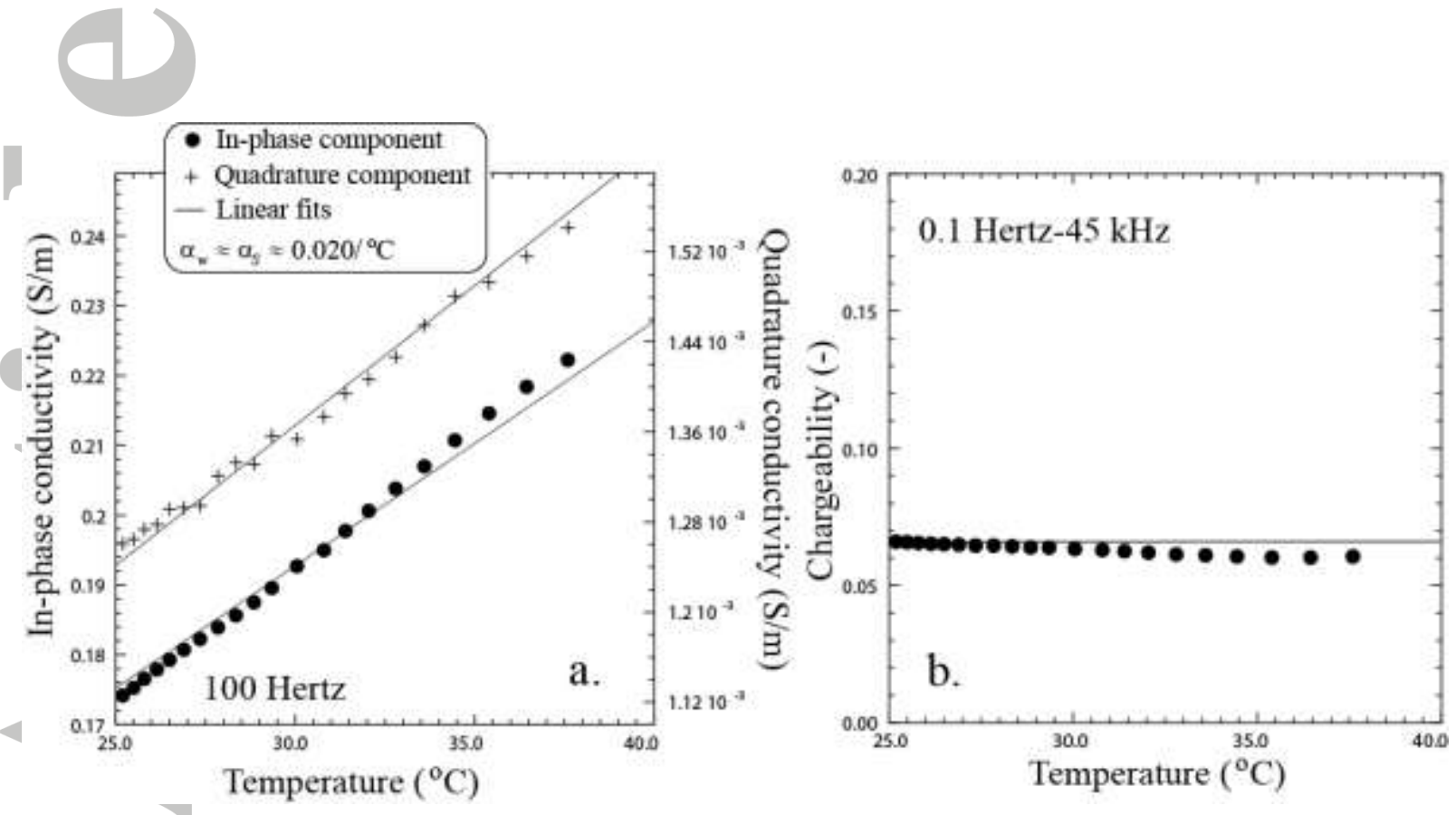

Figure 22. Influence of the temperature. a. Influence of the temperature on the magnitude of the in-phase and quadrature components of the complex conductivity. b. Influence of the temperature on the chargeability. As predicted by the dynamic Stern layer model, the chargeability is nearly temperature independent. 

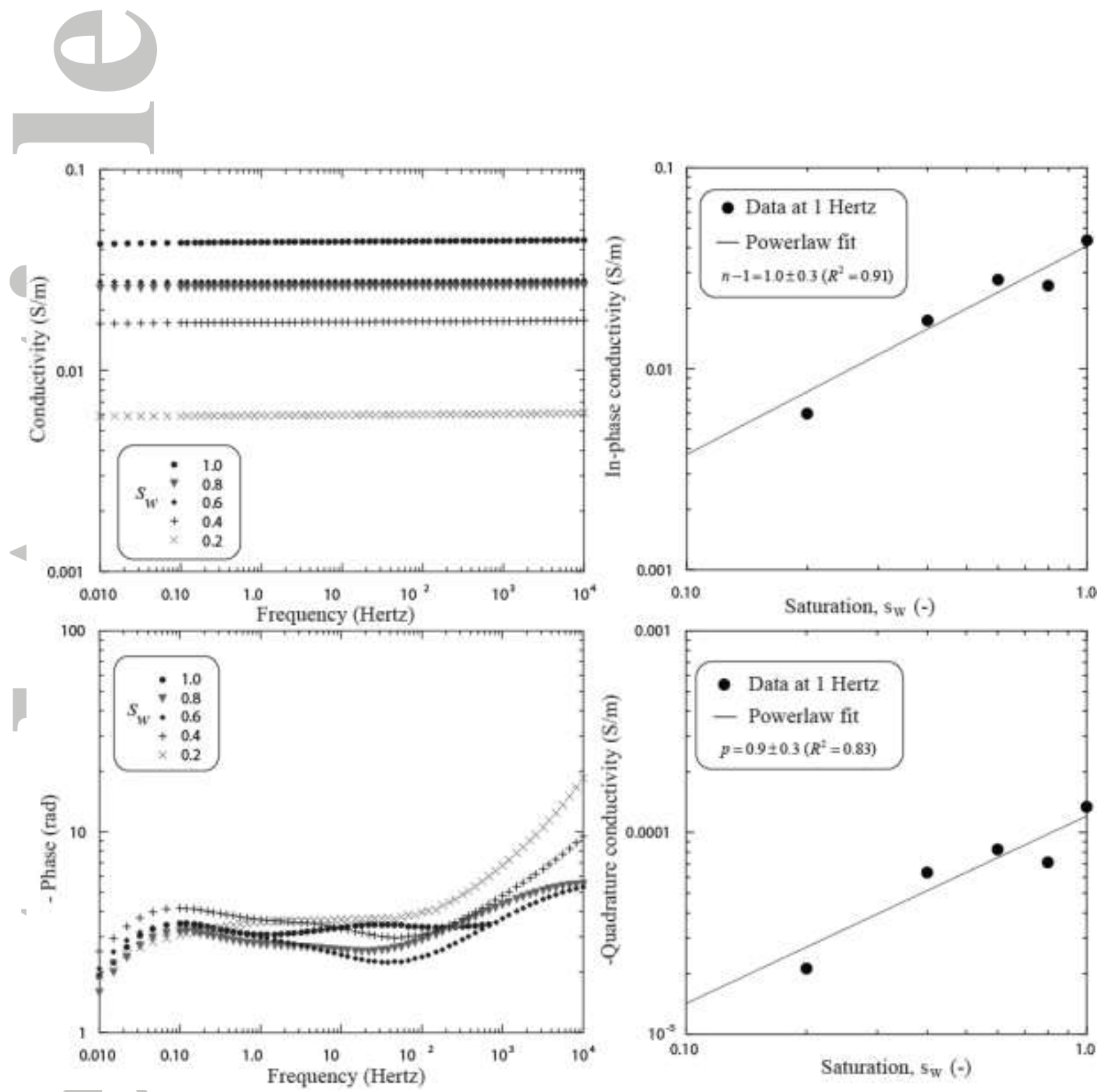

Figure 23. Saturation dependence of the complex conductivity at low salinity. Left side: Saturation dependence of the conductivity and phase spectra at low salinity (each curve corresponds to a distinct core sample). While the conductivity changes with the saturation, the phase is roughly constant as expected from the model. Left side: saturation dependence of the in-phase and quadrature conductivities $(1 \mathrm{Hertz})$ at low salinity. Note that the saturation exponents $(n-1)$ and $p$ are roughly the same (1.0 versus 0.9$)$ in agreement with the model (Sample AY, fine sand, pore water conductivity $0.06 \mathrm{~S} \mathrm{~m}^{-1}$ ).

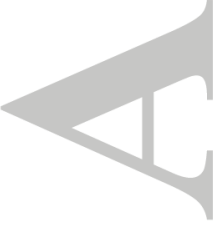




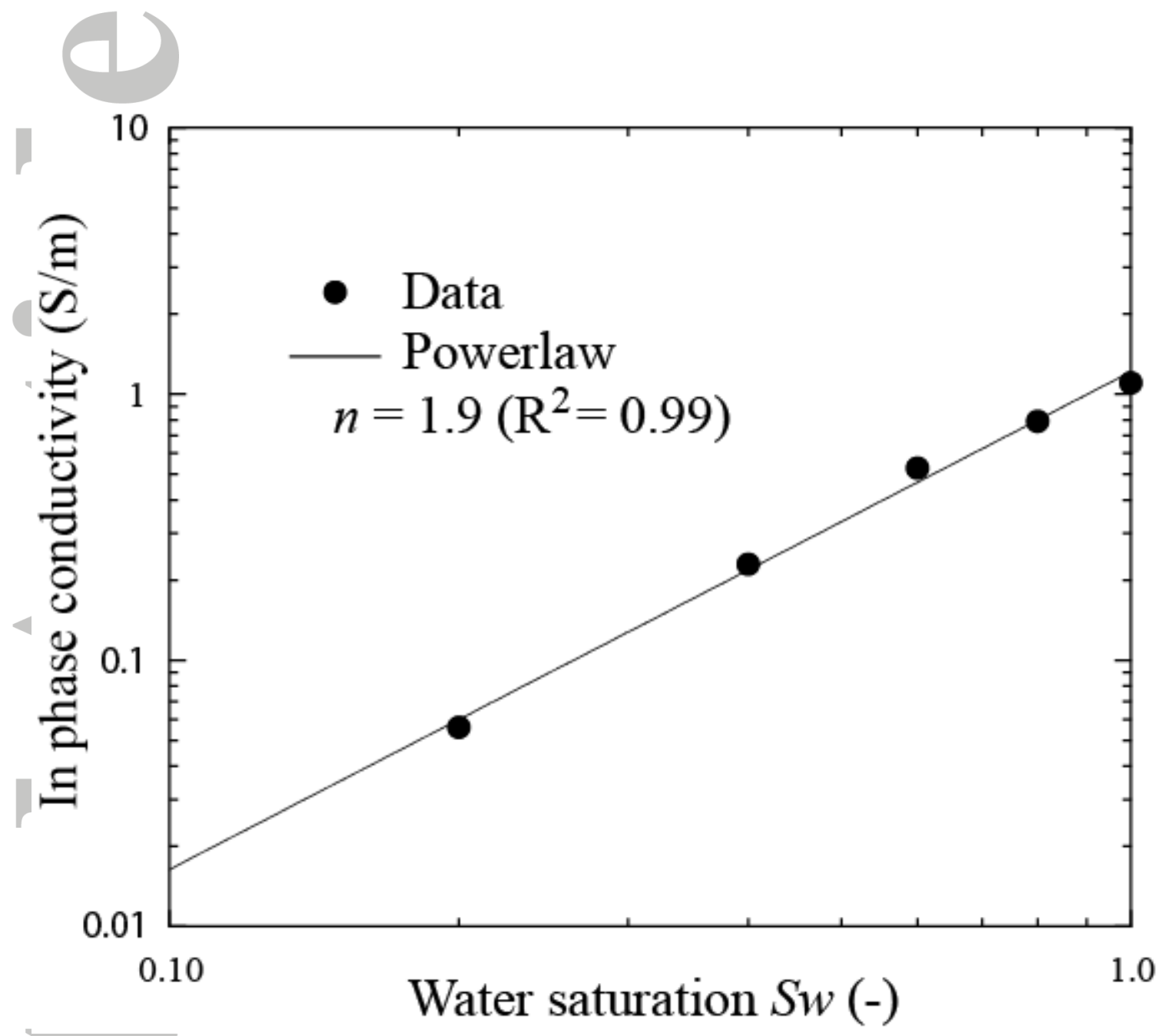

Figure 24. Saturation dependence of the in phase conductivity (1 Hertz)) at high salinity ( $\mathrm{NaCl}$ solution at $5 \mathrm{~S} \mathrm{~m}^{-1}$, sample $\mathrm{BB}$, fine sand). The dependence is used to determine the second Archie's exponent $n$. 